\title{
Total synthesis of the potent antitumor polyketide (-)-callystatin $A^{\#}$
}

\author{
Luiz C. Dias,* and Paulo R. R. Meira \\ Instituto de Química, Universidade Estadual de Campinas, UNICAMP \\ C.P. 6154, 13084-971, Campinas, SP, Brazil \\ E-mail: ldias@iqm.unicamp.br
}

\# Dedicated to Prof. Peter Bakuzis for his outstanding contributions to the field of synthetic organic chemistry in Brazil

\section{Supporting Information}

\begin{tabular}{|c|c|}
\hline CONTENTS & PAGE \\
\hline${ }^{1} \mathrm{H}$ NMR (500 MHz, $\mathrm{CDCl}_{3}$ ) - Aldol (29) & SI-66 \\
\hline${ }^{13} \mathrm{C}$ NMR (125 MHz, $\left.\mathrm{CDCl}_{3}\right)$ - Aldol (29) & SI-66 \\
\hline DEPT 90/135 (125 MHz, $\left.\mathrm{CDCl}_{3}\right)$ - Aldol (29) & SI-67 \\
\hline IR (film) - Aldol (29) & SI-67 \\
\hline${ }^{1} \mathrm{H}$ NMR (300 MHz, $\left.\mathrm{CDCl}_{3}\right)$ - Weinreb amide from (29) & SI-68 \\
\hline${ }^{13} \mathrm{C}$ NMR (75 MHz, $\left.\mathrm{CDCl}_{3}\right)$ - Weinreb amide from (29) & SI-68 \\
\hline DEPT 90/135 (75 MHz, $\left.\mathrm{CDCl}_{3}\right)$ - Weinreb amide from (29) & SI-69 \\
\hline IR (film) - Weinreb amide from (29) & SI-69 \\
\hline${ }^{1} \mathrm{H}$ NMR (300 MHz, $\left.\mathrm{CDCl}_{3}\right)$ - Weinreb amide (7) & SI-70 \\
\hline${ }^{13} \mathrm{C}$ NMR $\left(75 \mathrm{MHz} \mathrm{CDCl}_{3}\right)$ - Weinreb amide (7) & SI-70 \\
\hline DEPT 90/135 (75 MHz, CDCl 3$)$ - Weinreb amide (7) & SI-71 \\
\hline IR (film) - Weinreb amide (7) & SI-71 \\
\hline${ }^{1} \mathrm{H}$ NMR (300 MHz, $\left.\mathrm{CDCl}_{3}\right)$ - Unsaturated ester (30) & SI-72 \\
\hline${ }^{13} \mathrm{C}$ NMR (75 MHz, CDCl 3 ) - Unsaturated ester (30) & SI-72 \\
\hline DEPT 90/135 (75 MHz, CDCl $)$ - Unsaturated ester (30) & SI-73 \\
\hline IR (film) - Unsaturated ester (30) & SI-73 \\
\hline
\end{tabular}




\begin{tabular}{|c|c|}
\hline${ }^{1} \mathrm{H}$ NMR (300 MHz, $\left.\mathrm{CDCl}_{3}\right)$ - Allylic alcohol (6) & SI-74 \\
\hline${ }^{13} \mathrm{C}$ NMR (75 MHz, $\mathrm{CDCl}_{3}$ ) - Allylic alcohol (6) & SI-74 \\
\hline DEPT 90/135 (75 MHz, $\left.\mathrm{CDCl}_{3}\right)$ - Allylic alcohol (6) & SI-75 \\
\hline IR (film) - Allylic alcohol (6) & SI-75 \\
\hline${ }^{1} \mathrm{H}$ NMR (300 MHz, $\mathrm{CDCl}_{3}$ ) - Epoxide (31) & SI-76 \\
\hline${ }^{13} \mathrm{C}$ NMR (75 MHz, $\mathrm{CDCl}_{3}$ ) - Epoxide (31) & SI-76 \\
\hline DEPT 90/135 (75 MHz, $\mathrm{CDCl}_{3}$ ) - Epoxide (31) & SI-77 \\
\hline IR (film) - Epoxide (31) & SI-77 \\
\hline${ }^{1} \mathrm{H}$ NMR (300 MHz, $\mathrm{CDCl}_{3}$ ) - Diol (32) & SI-78 \\
\hline${ }^{13} \mathrm{C}$ NMR (75 MHz, $\mathrm{CDCl}_{3}$ ) - Diol (32) & SI-78 \\
\hline DEPT 90/135 (75 MHz, CDCl $\left.{ }_{3}\right)$ - Diol (32) & SI-79 \\
\hline IR (film) - Diol (32) & SI-79 \\
\hline${ }^{1} \mathrm{H}$ NMR (300 MHz, $\mathrm{CDCl}_{3}$ ) - Diol (34) & SI-80 \\
\hline${ }^{13} \mathrm{C}$ NMR (75 MHz, $\mathrm{CDCl}_{3}$ ) - Diol (34) & SI-80 \\
\hline DEPT 90/135 (75 MHz, CDCl ${ }_{3}$ ) - Diol (34) & SI-81 \\
\hline${ }^{1} \mathrm{H}$ NMR (300 MHz, $\mathrm{CDCl}_{3}$ ) - Acetonide (35) & SI-81 \\
\hline${ }^{13} \mathrm{C}$ NMR (75 MHz, $\mathrm{CDCl}_{3}$ ) - Acetonide (35) & SI-82 \\
\hline DEPT 90/135 (75 MHz, $\left.\mathrm{CDCl}_{3}\right)$ - Acetonide (35) & SI-82 \\
\hline${ }^{1} \mathrm{H}$ NMR (300 MHz, $\mathrm{CDCl}_{3}$ ) - Acetal (33) & SI-83 \\
\hline${ }^{13} \mathrm{C}$ NMR (75 MHz, $\mathrm{CDCl}_{3}$ ) - Acetal (33) & SI-83 \\
\hline${ }^{1} \mathrm{H}$ NMR (300 MHz, $\left.\mathrm{CDCl}_{3}\right)$ - Unsaturated ester (37) & SI-84 \\
\hline${ }^{13} \mathrm{C}$ NMR (75 MHz, $\mathrm{CDCl}_{3}$ ) - Unsaturated ester (37) & SI-84 \\
\hline DEPT 90/135 (75 MHz, $\left.\mathrm{CDCl}_{3}\right)$ - Unsaturated ester (37) & SI-85 \\
\hline${ }^{1} \mathrm{H}$ NMR (300 MHz, $\mathrm{CDCl}_{3}$ ) - Allylic alcohol from (37) & SI-85 \\
\hline${ }^{13} \mathrm{C}$ NMR (75 MHz, $\mathrm{CDCl}_{3}$ ) - Allylic alcohol from (37) & SI-86 \\
\hline DEPT 90/135 (75 MHz, CDCl 3 ) - Allylic alcohol from (37) & SI-86 \\
\hline${ }^{1} \mathrm{H}$ NMR (300 MHz, $\left.\mathrm{CDCl}_{3}\right)-(E)$-Vinyl iodide (3) & SI-87 \\
\hline${ }^{13} \mathrm{C}$ NMR $\left(75 \mathrm{MHz} \mathrm{CDCl}_{3}\right)-(E)$-Vinyl iodide (3) & SI-88 \\
\hline DEPT 90/135 (75 MHz, $\left.\mathrm{CDCl}_{3}\right)$ - (E)-Vinyl iodide (3) & SI-88 \\
\hline${ }^{1} \mathrm{H}$ NMR $\left(300 \mathrm{MHz}, \mathrm{CDCl}_{3}\right)-(E)$-Vinyl iodide (39) & SI-89 \\
\hline${ }^{13} \mathrm{C}$ NMR (75 MHz, $\left.\mathrm{CDCl}_{3}\right)-(E)$-Vinyl iodide (39) & SI-89 \\
\hline${ }^{1} \mathrm{H}$ NMR (300 MHz, $\left.\mathrm{CDCl}_{3}\right)$ - Callystatin A (1) & SI-90 \\
\hline
\end{tabular}




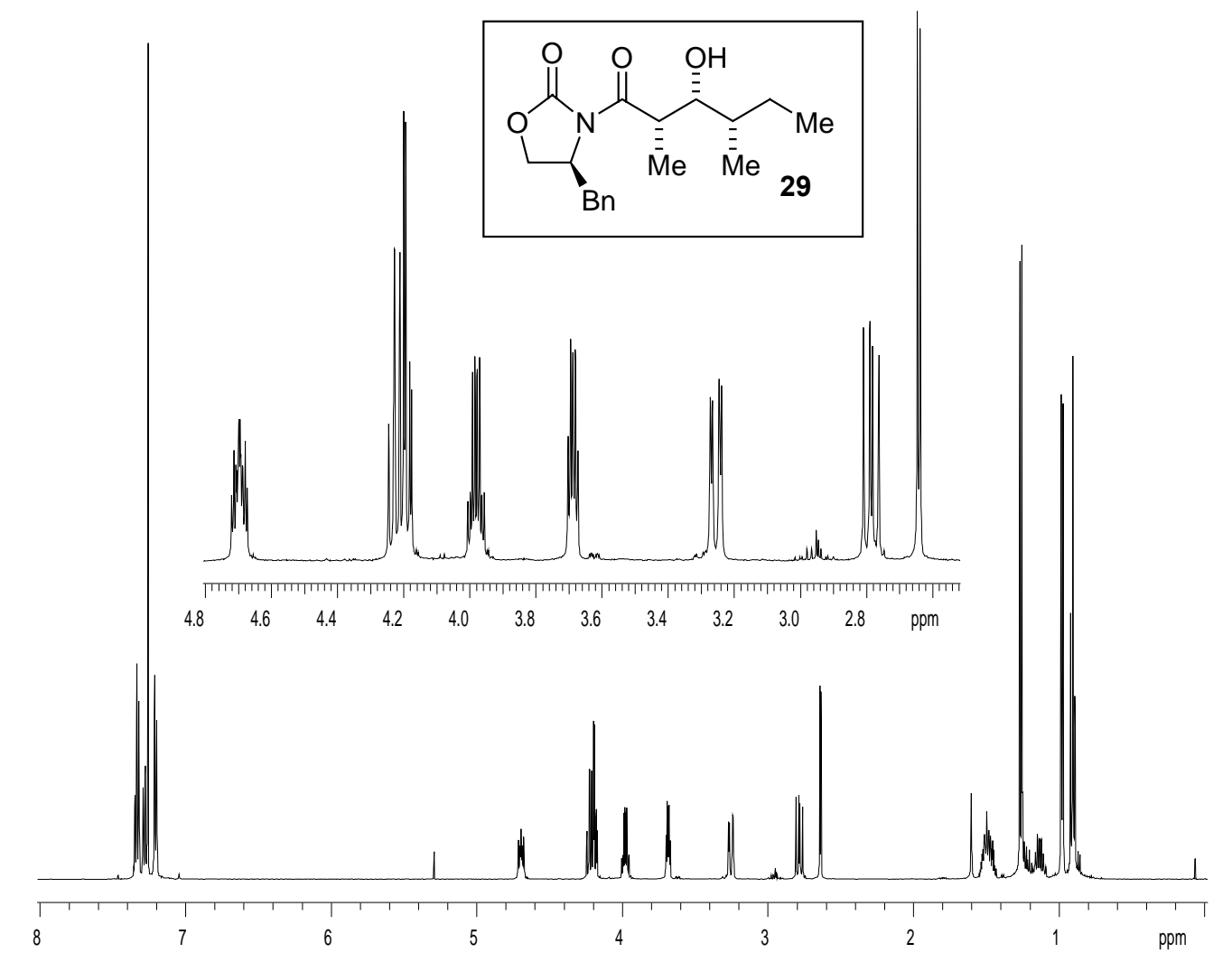

${ }^{1} \mathrm{H}$ NMR (500 MHz, $\mathrm{CDCl}_{3}$ ) - Aldol (29)

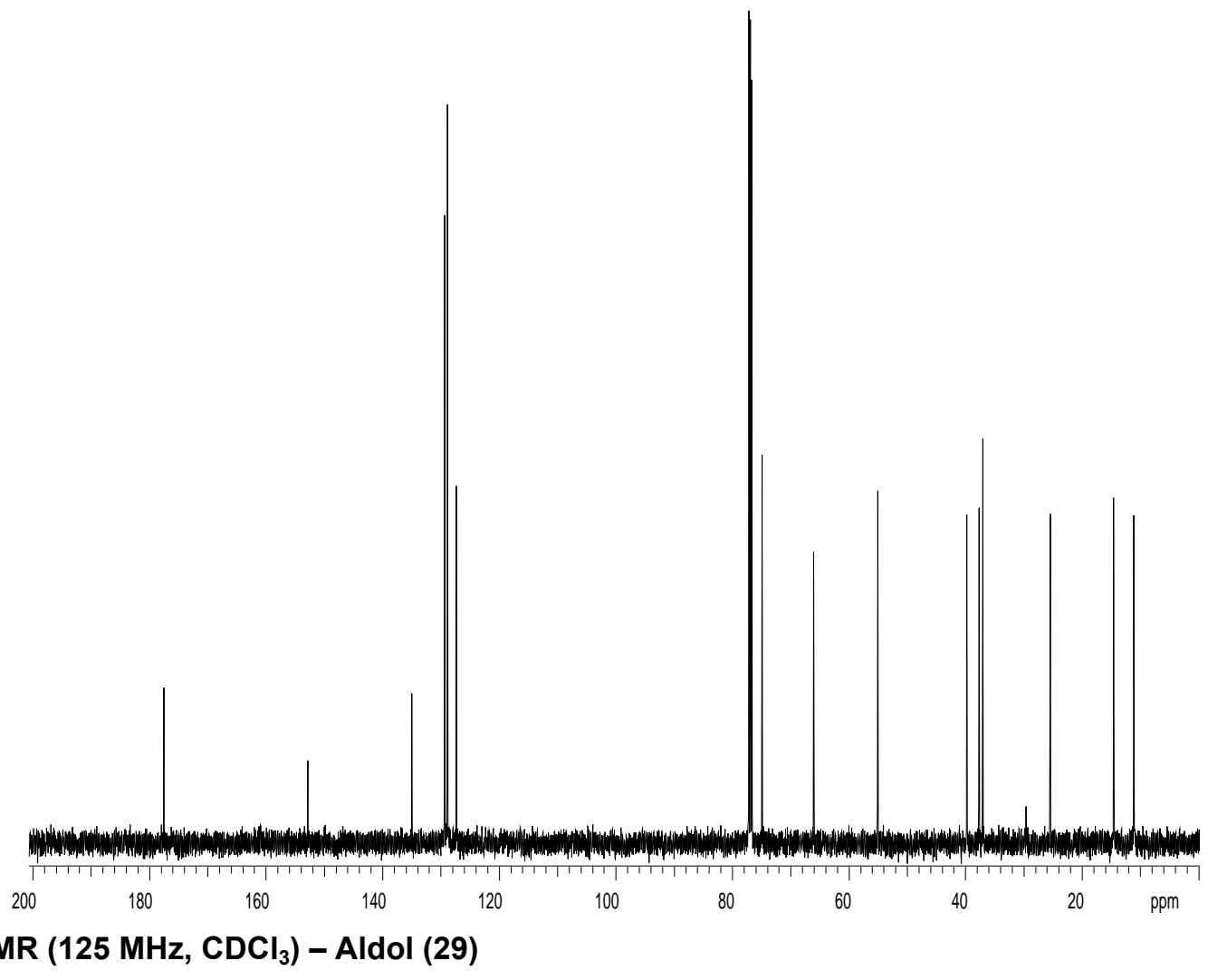



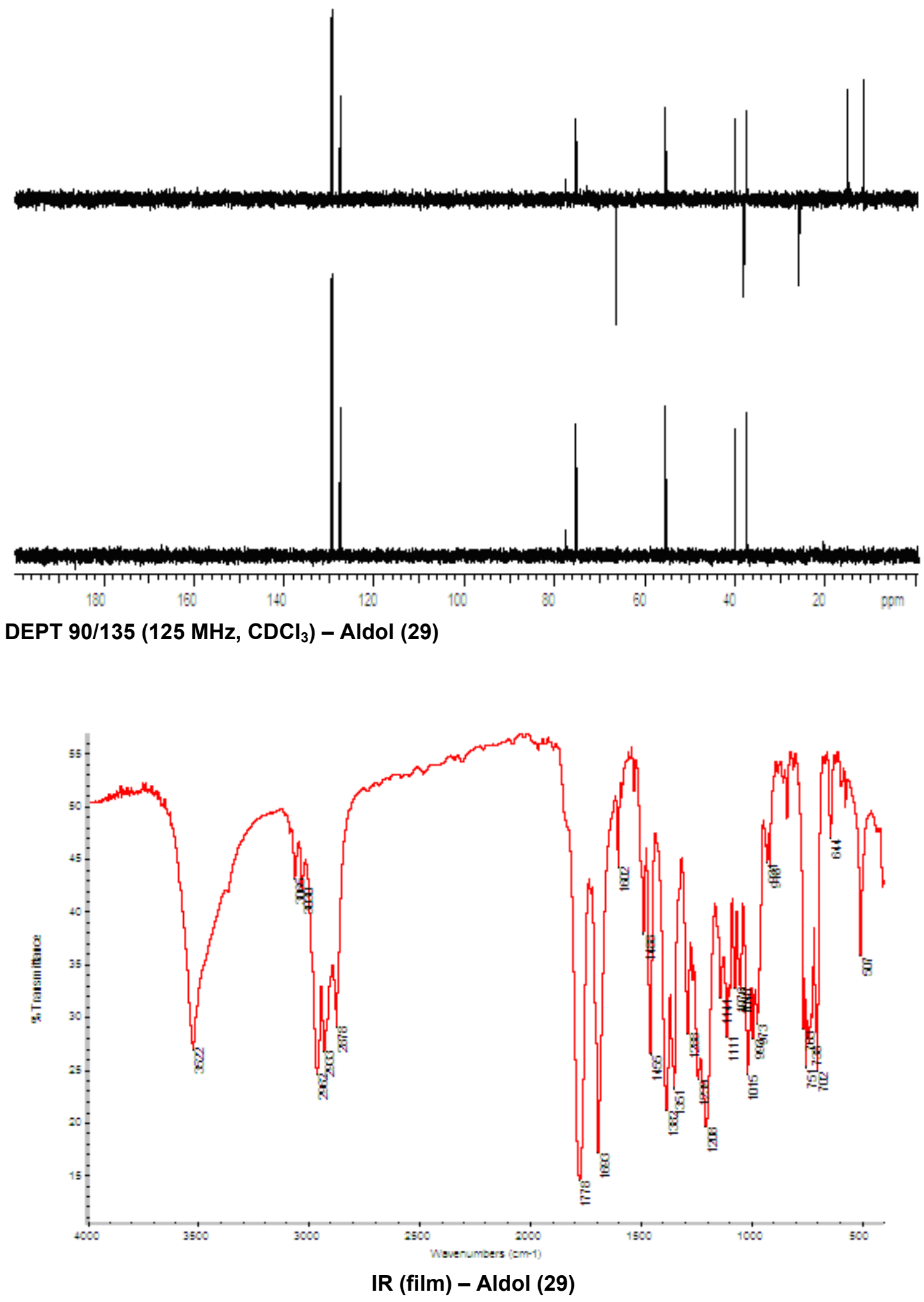


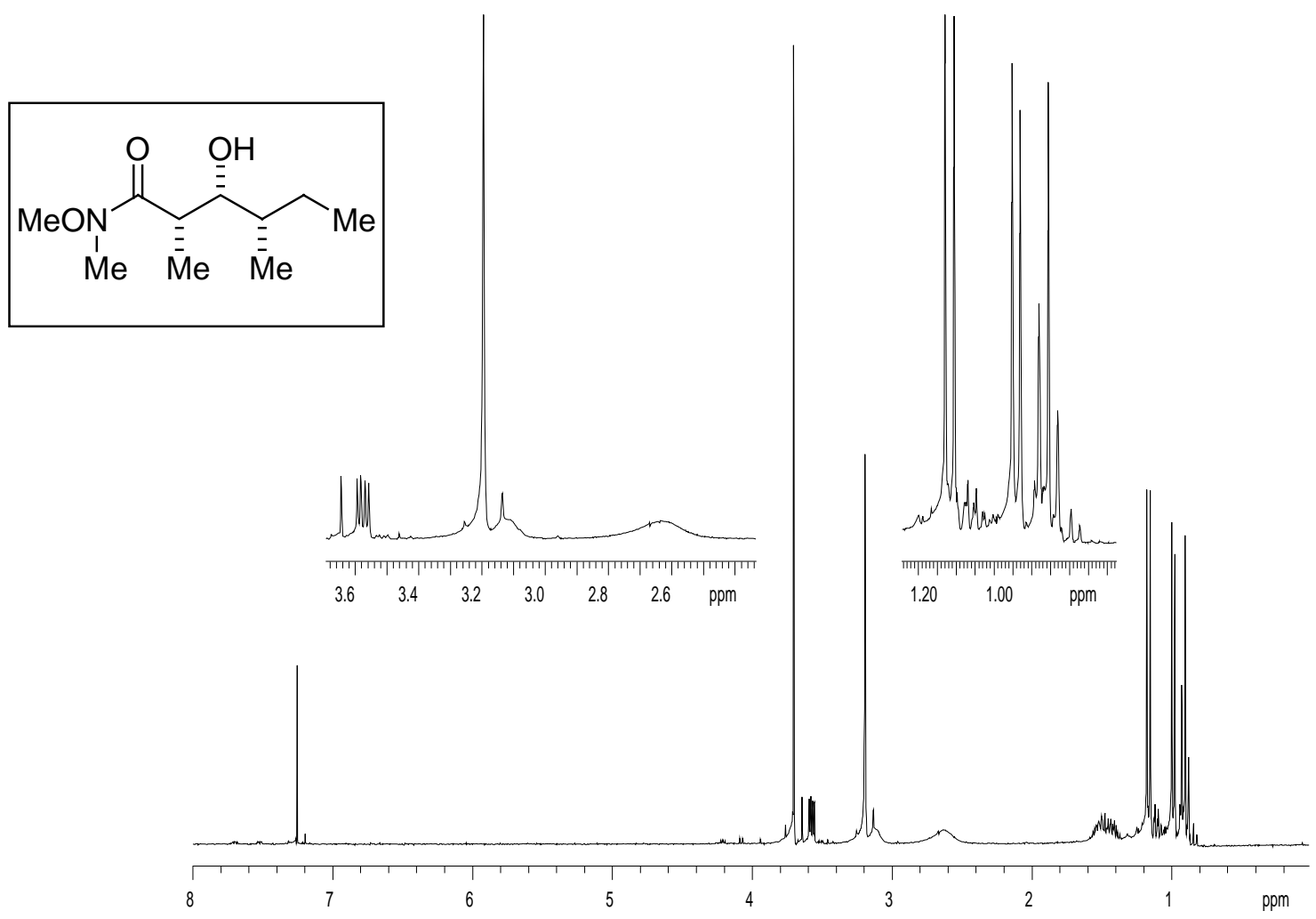

${ }^{1} \mathrm{H}$ NMR (300 MHz, $\mathrm{CDCl}_{3}$ ) - Weinreb amide from (29)

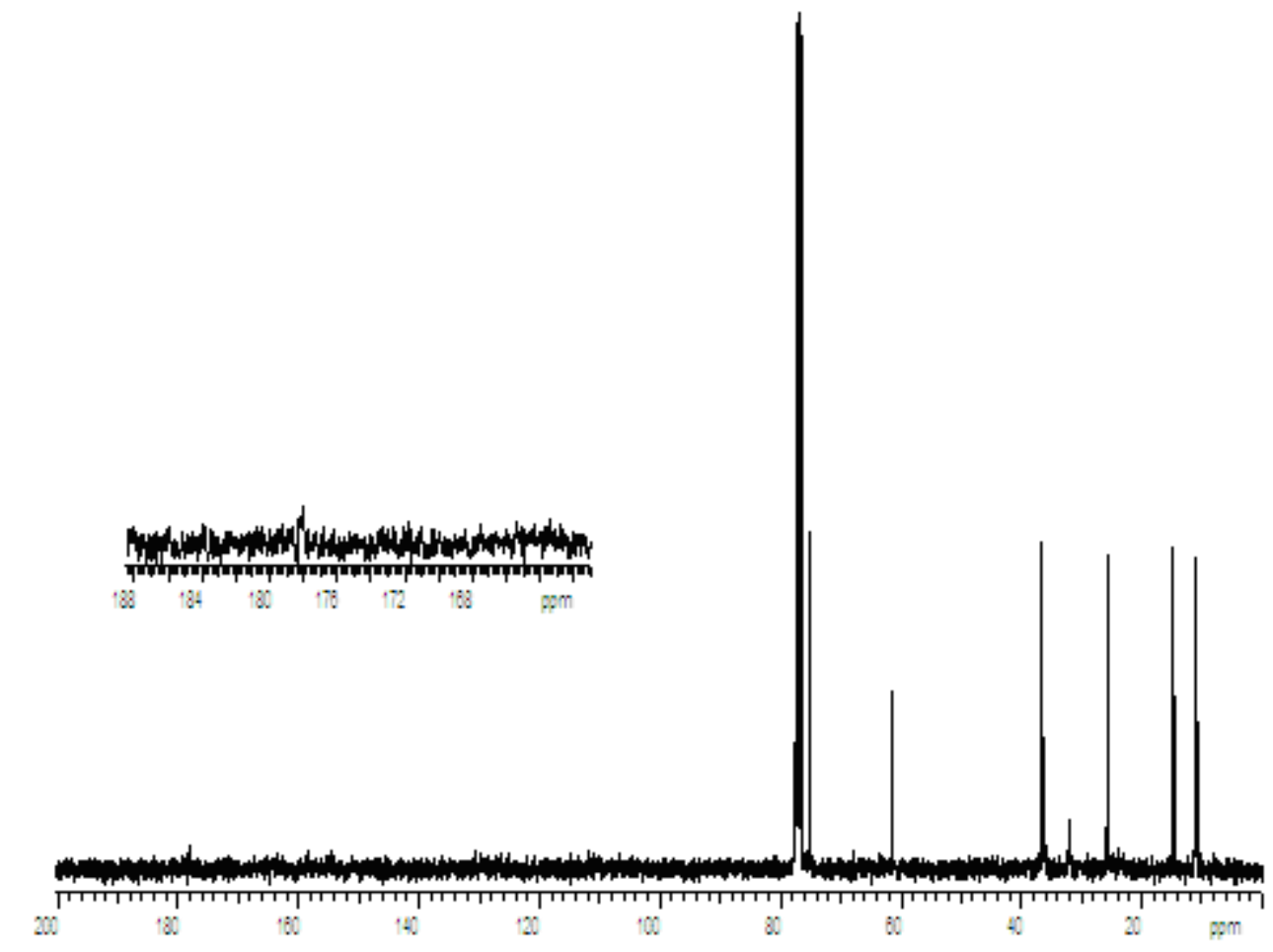

${ }^{13} \mathrm{C}$ NMR (75 MHz, $\left.\mathrm{CDCl}_{3}\right)$ - Weinreb amide from (29) 


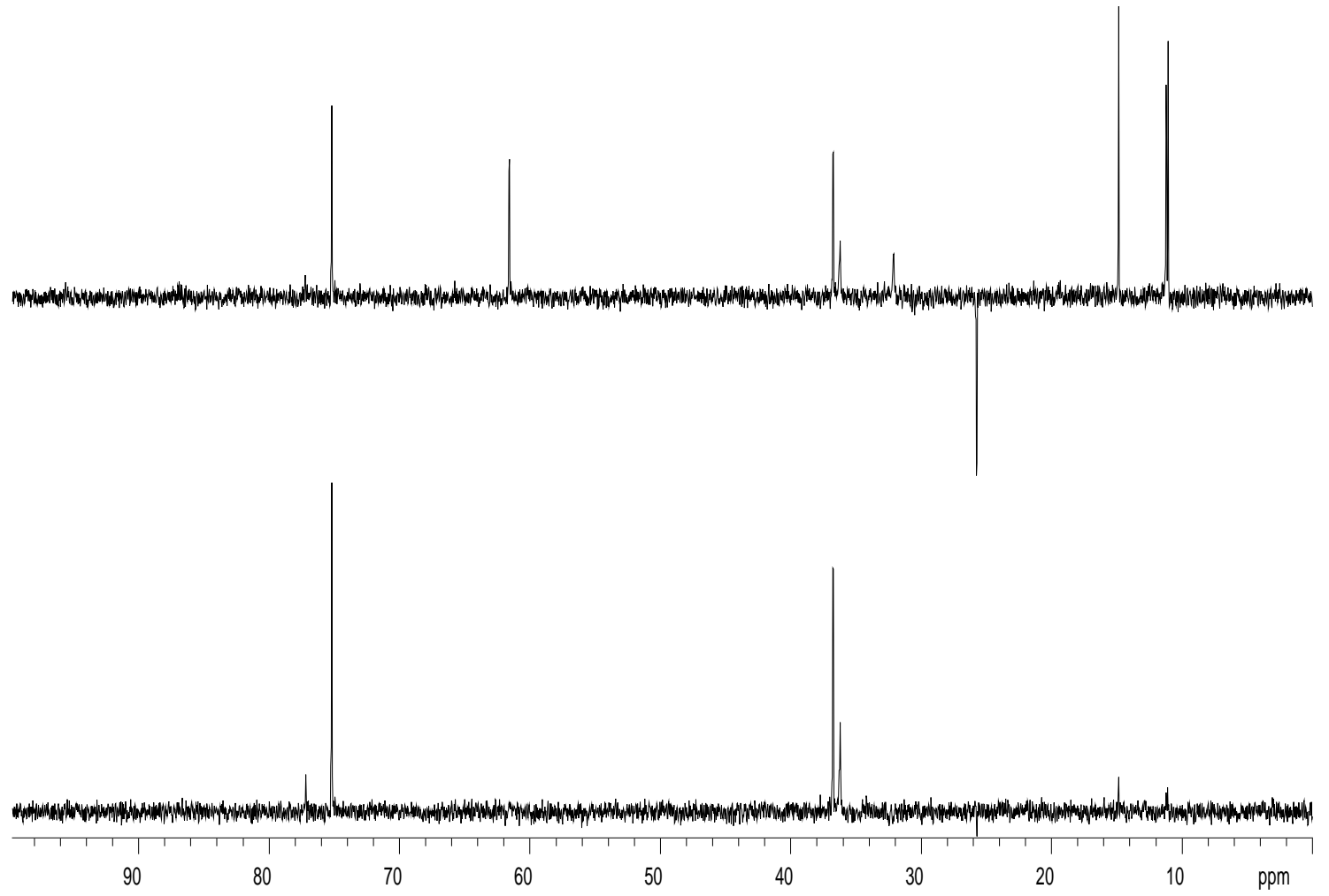

DEPT 90/135 (75 MHz, $\mathrm{CDCl}_{3}$ ) - Weinreb amide from (29)

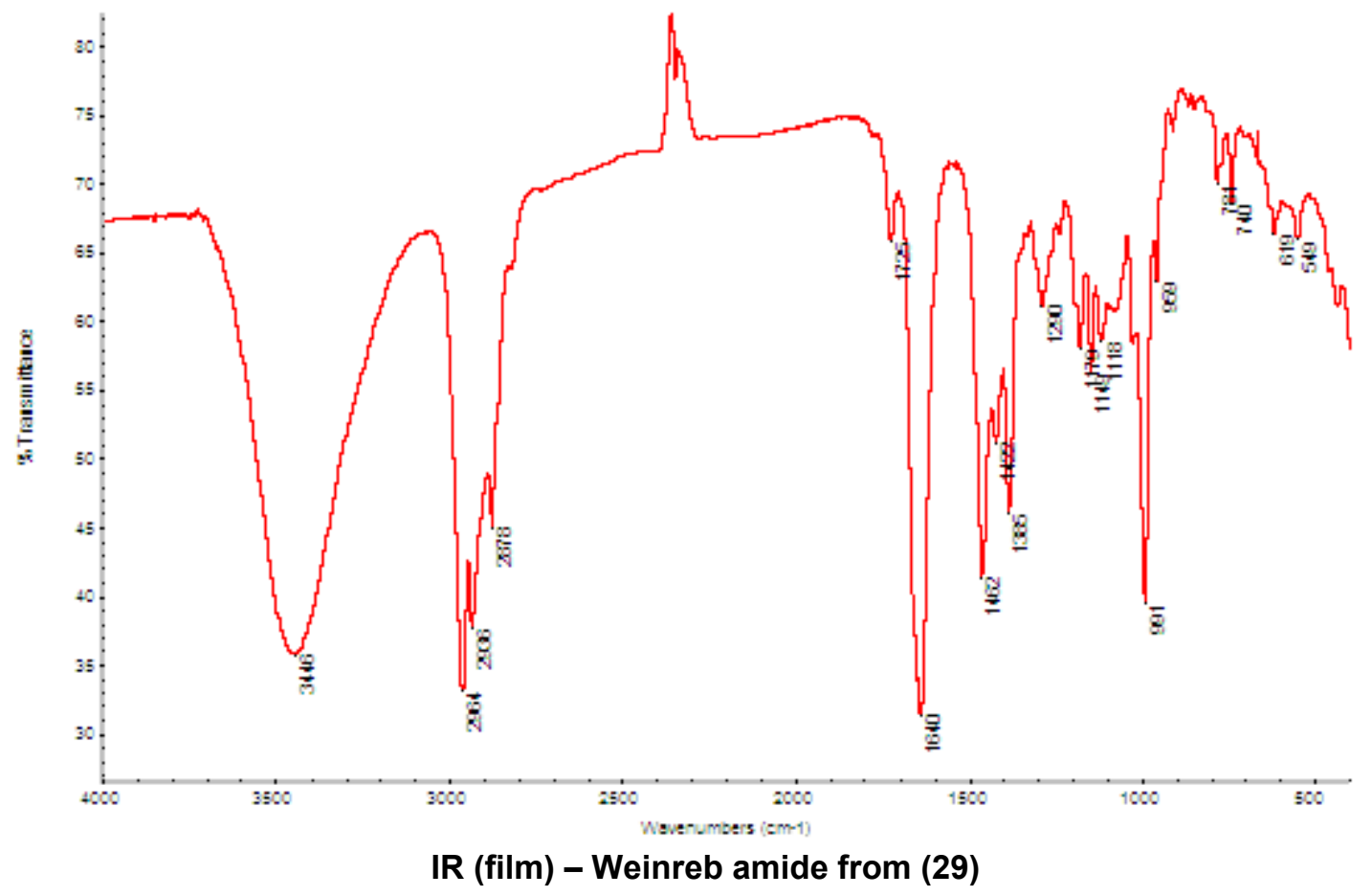




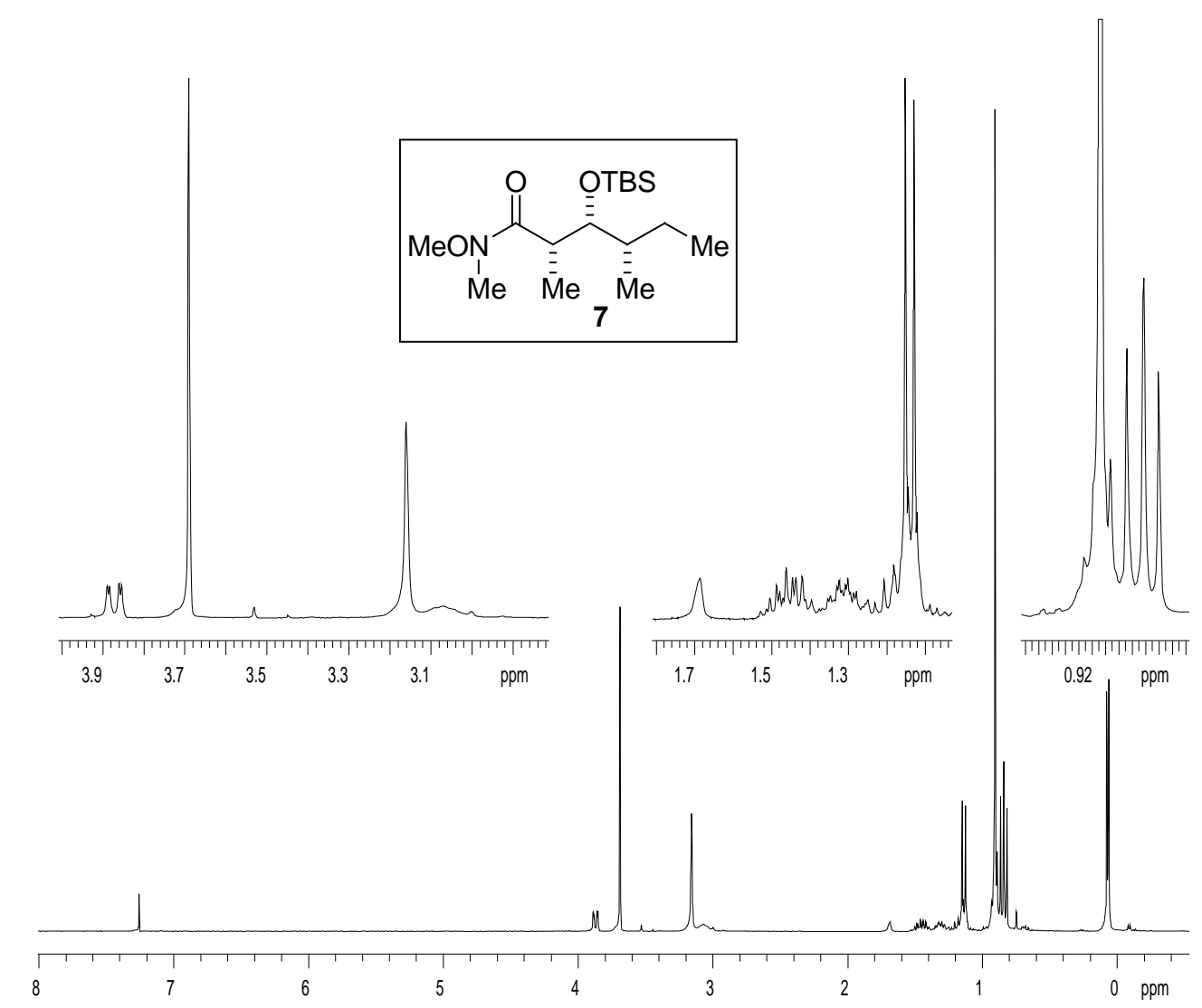

${ }^{1} \mathrm{H}$ NMR (300 MHz, $\left.\mathrm{CDCl}_{3}\right)$ - Weinreb amide (7)

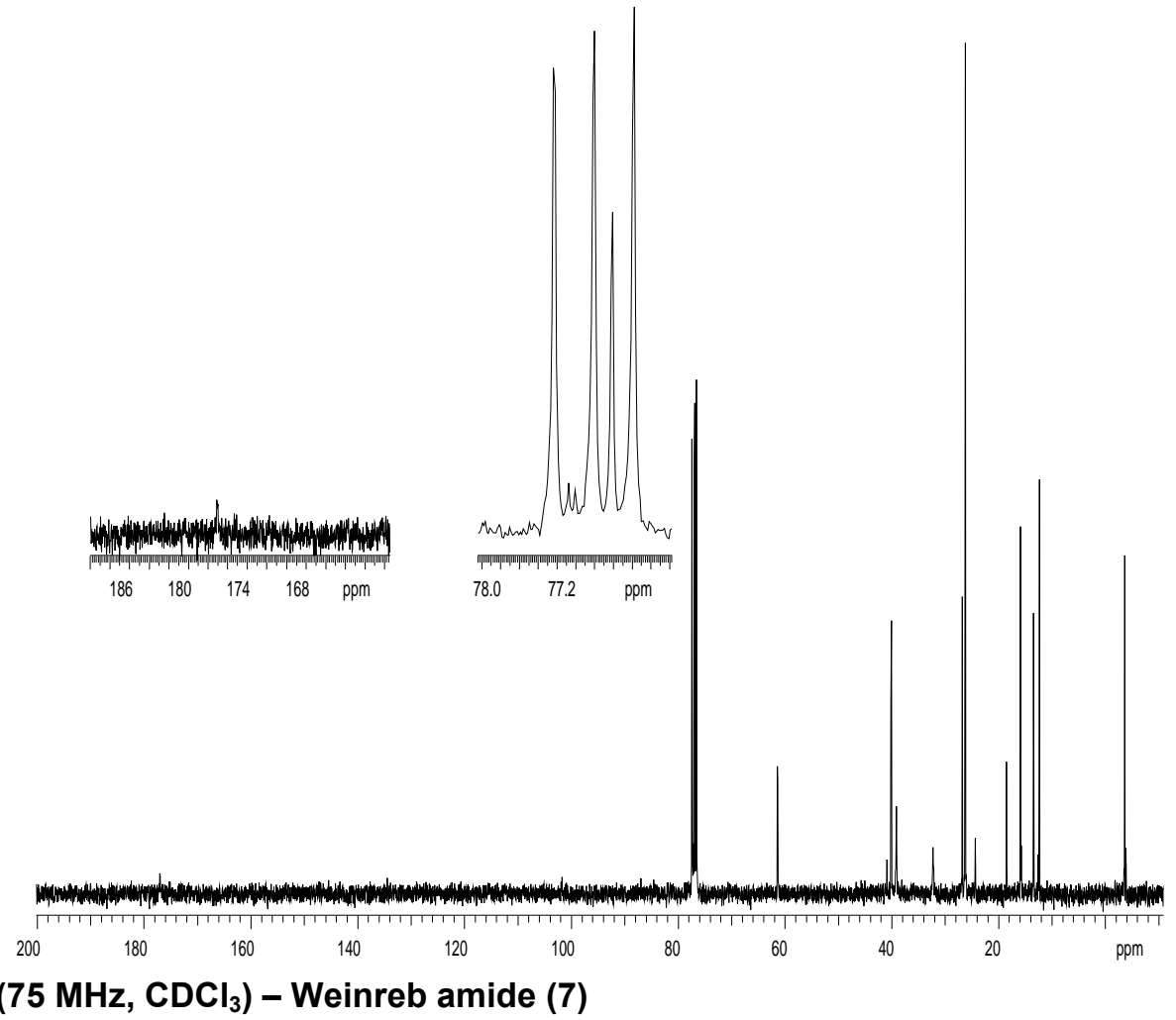



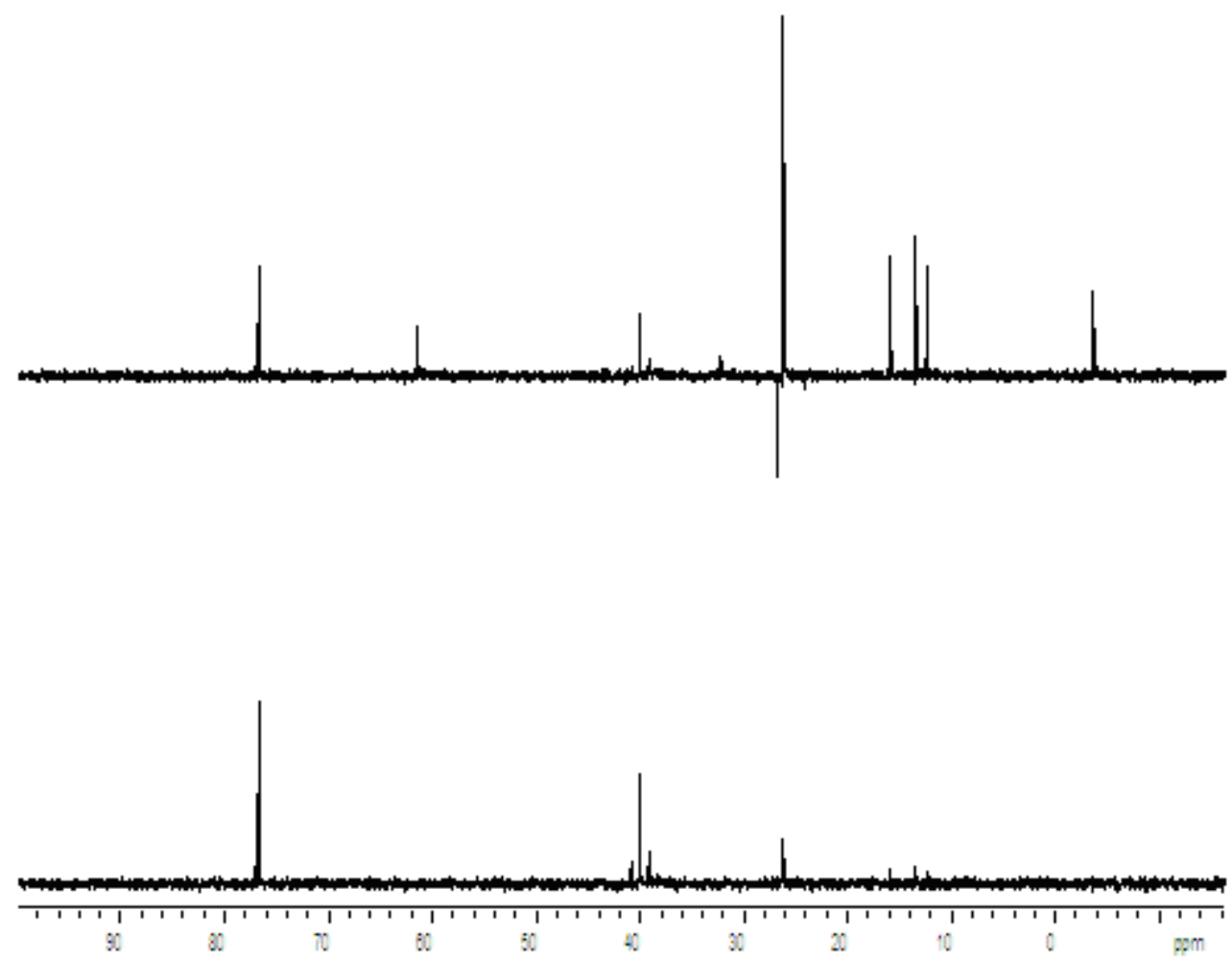

DEPT 90/135 (75 MHz, $\left.\mathrm{CDCl}_{3}\right)$ - Weinreb amide (7)

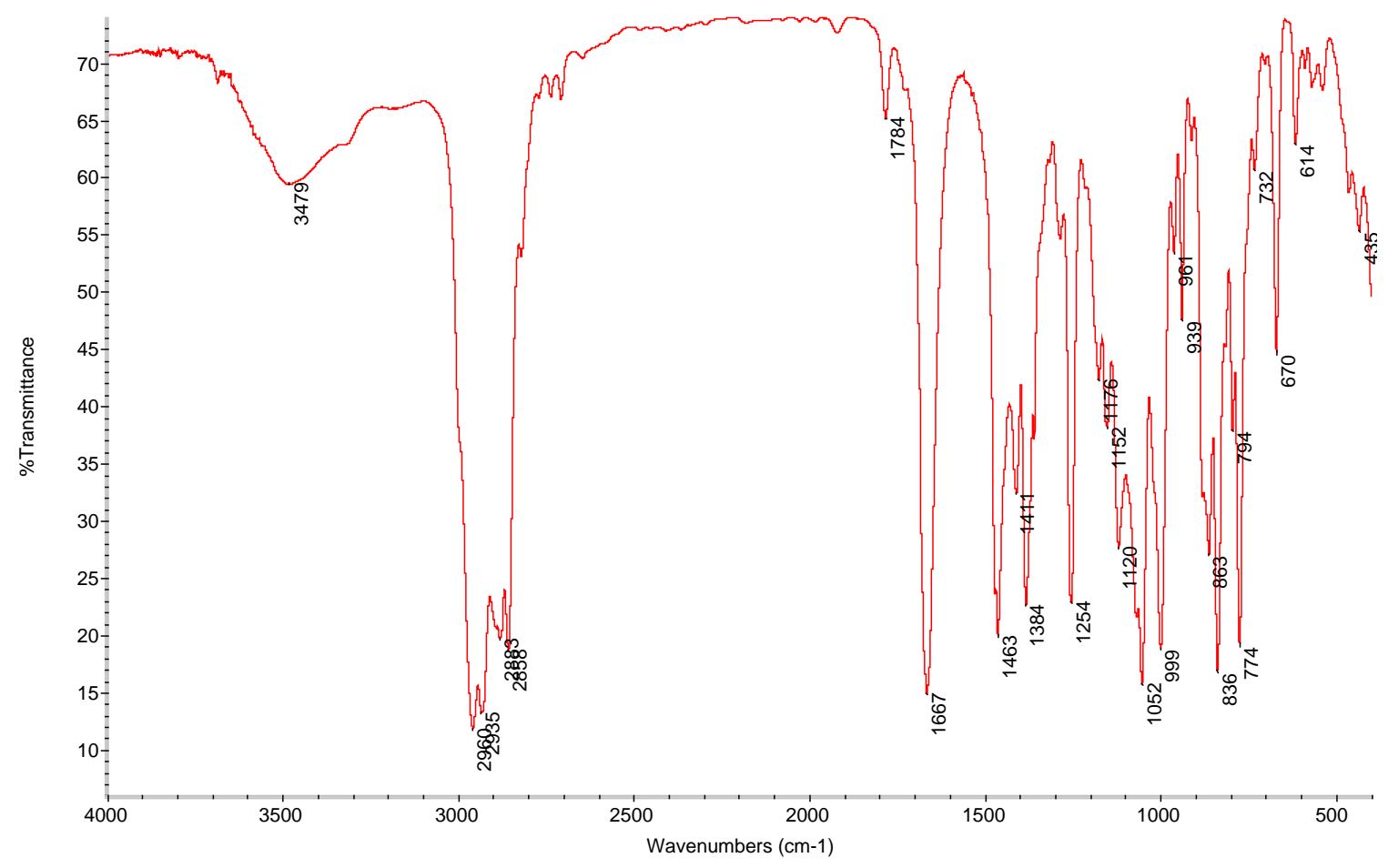

IR (film) - Weinreb amide (7) 


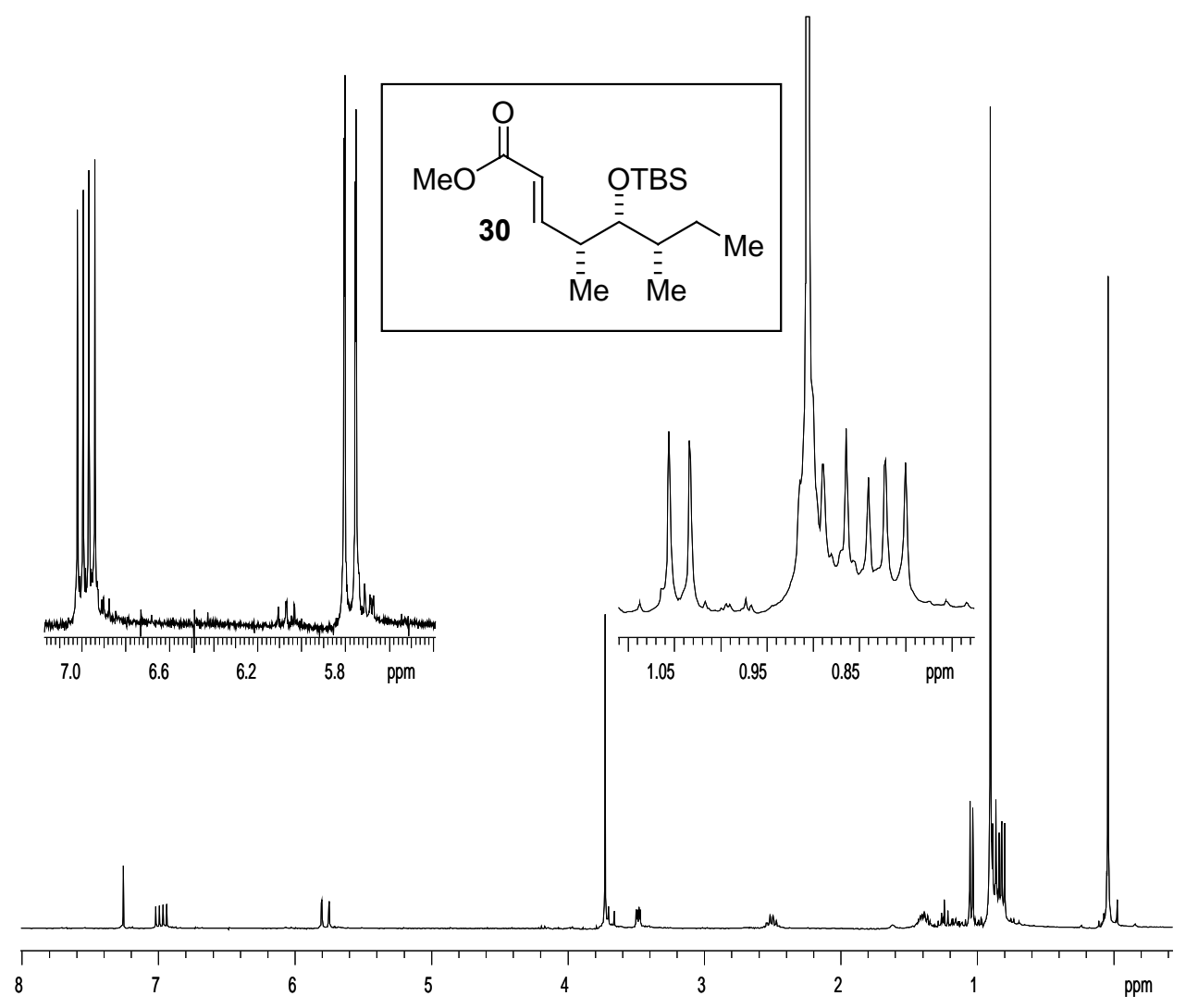

${ }^{1} \mathrm{H}$ NMR (300 MHz, $\mathrm{CDCl}_{3}$ ) - Unsaturated ester (30)

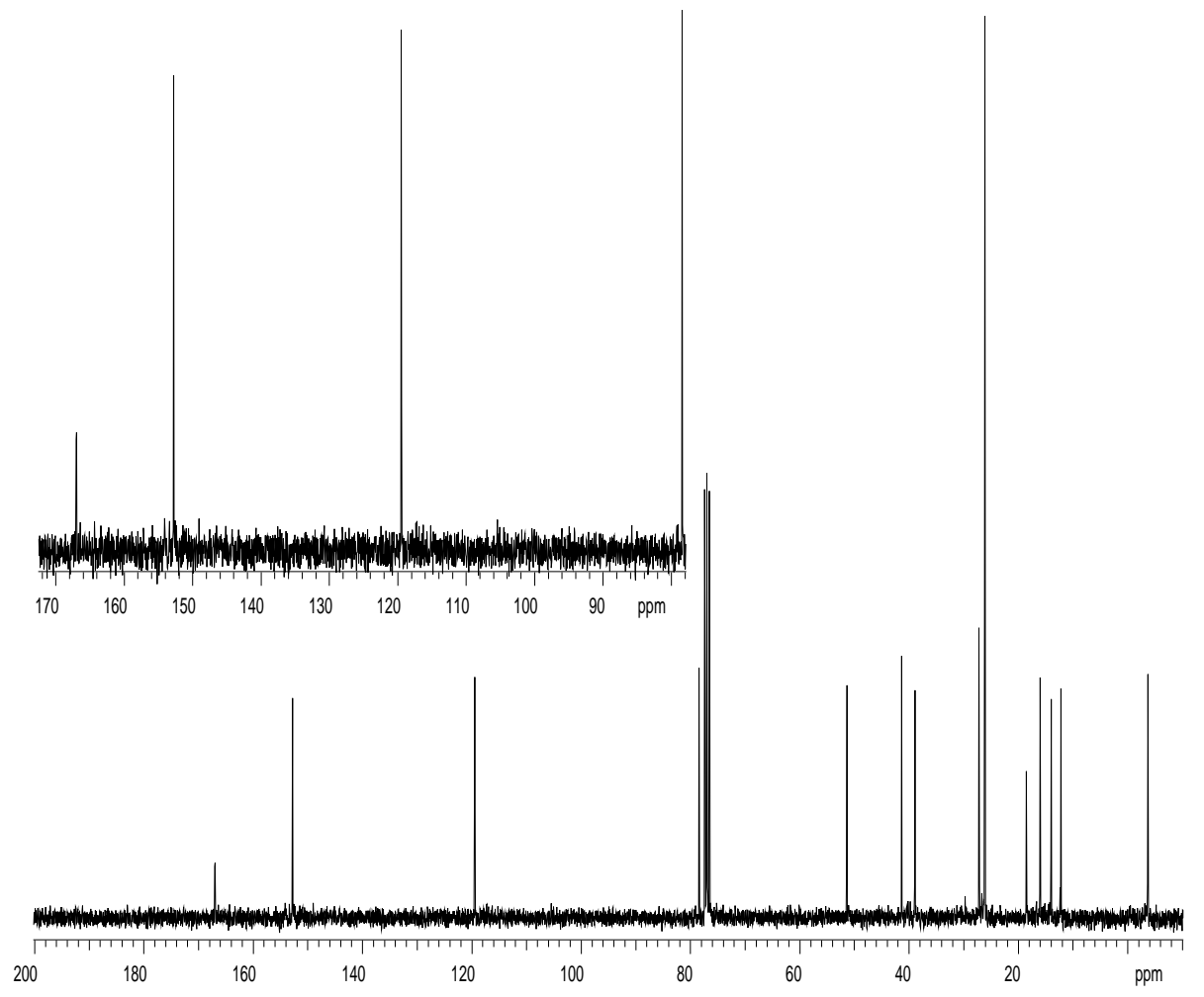

${ }^{13} \mathrm{C}$ NMR (75 MHz, $\mathrm{CDCl}_{3}$ ) - Unsaturated ester (30) 

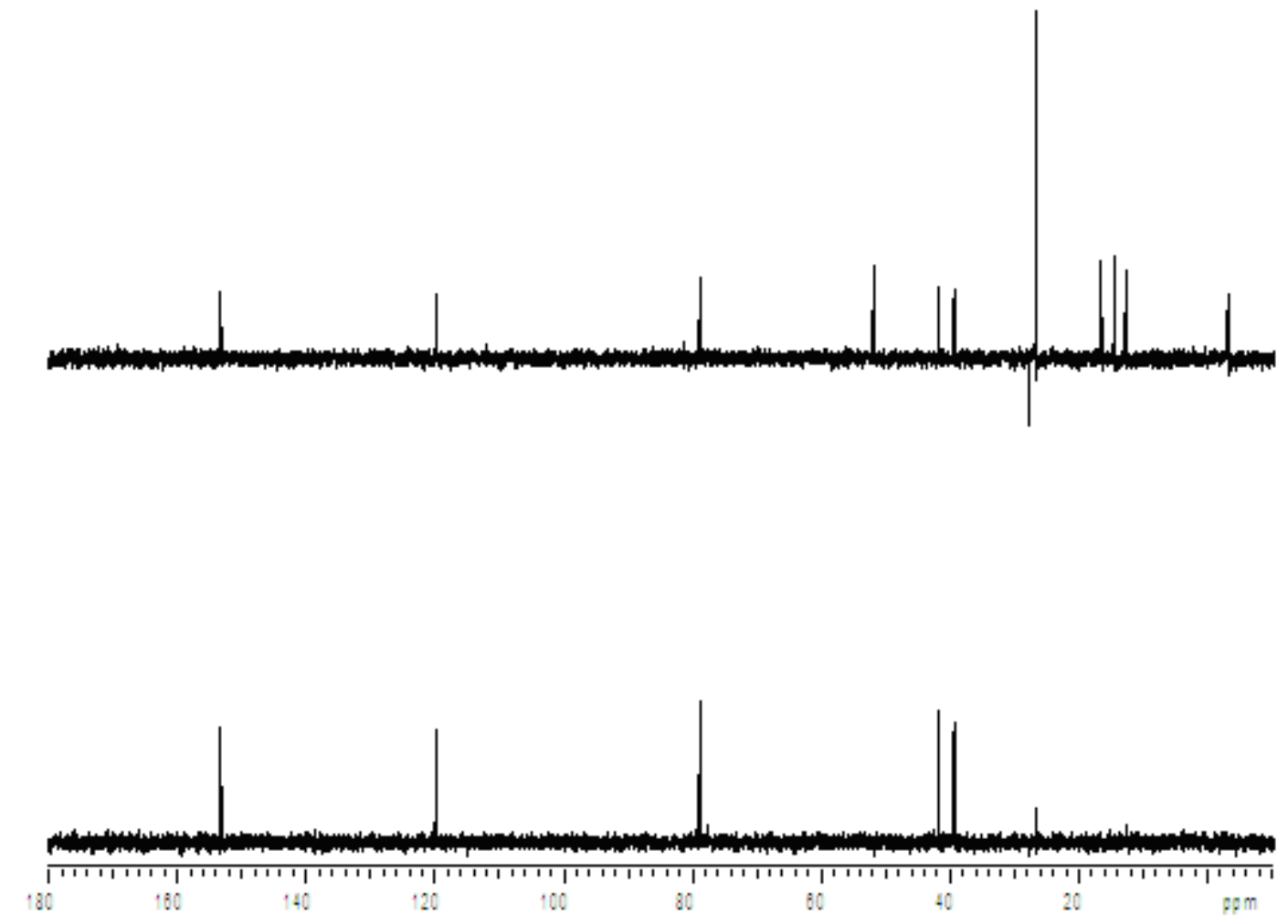

DEPT 90/135 (75 MHz, $\mathrm{CDCl}_{3}$ ) - Unsaturated ester (30)

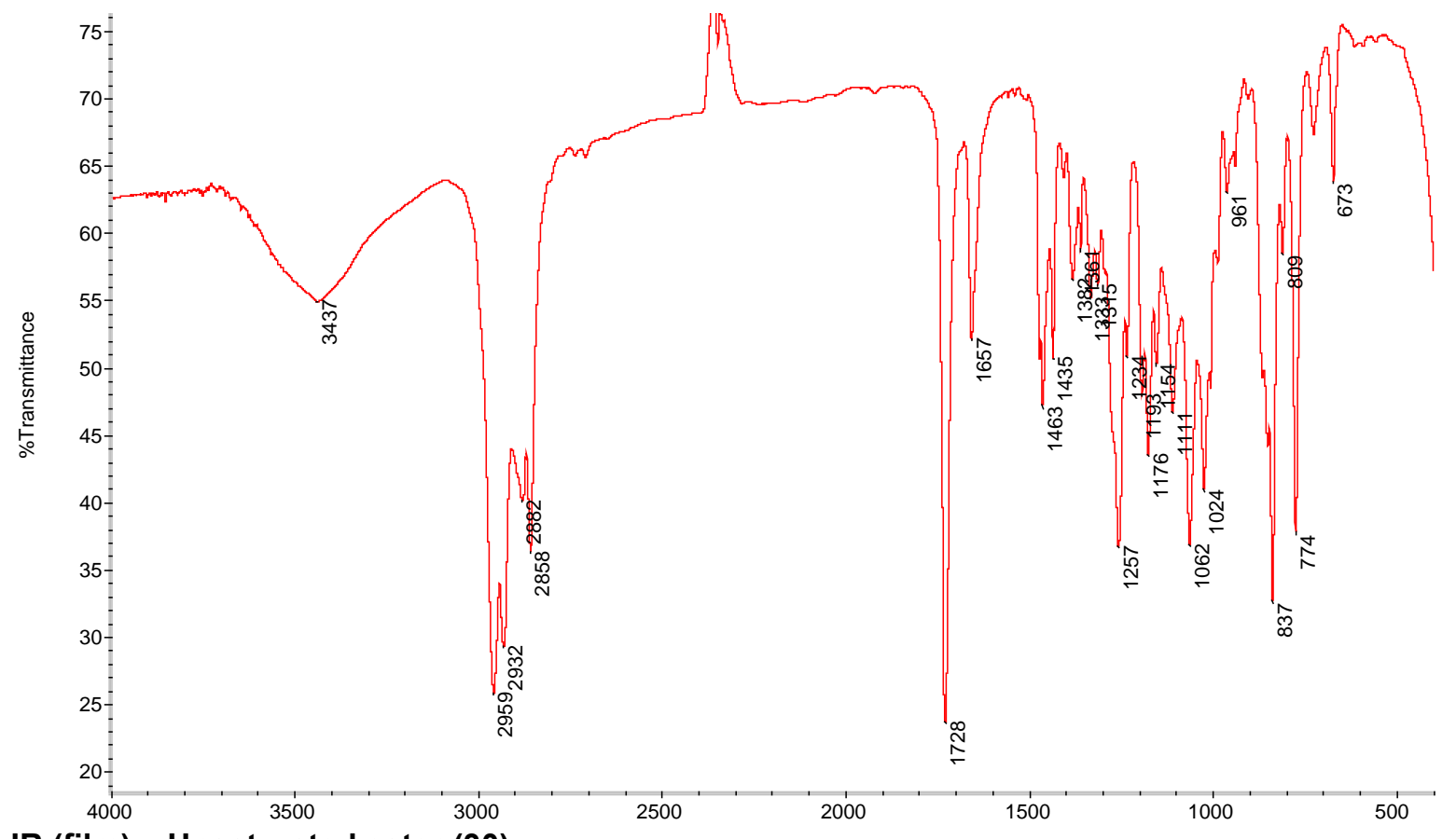

IR (film) - Unsaturated ester (30) 


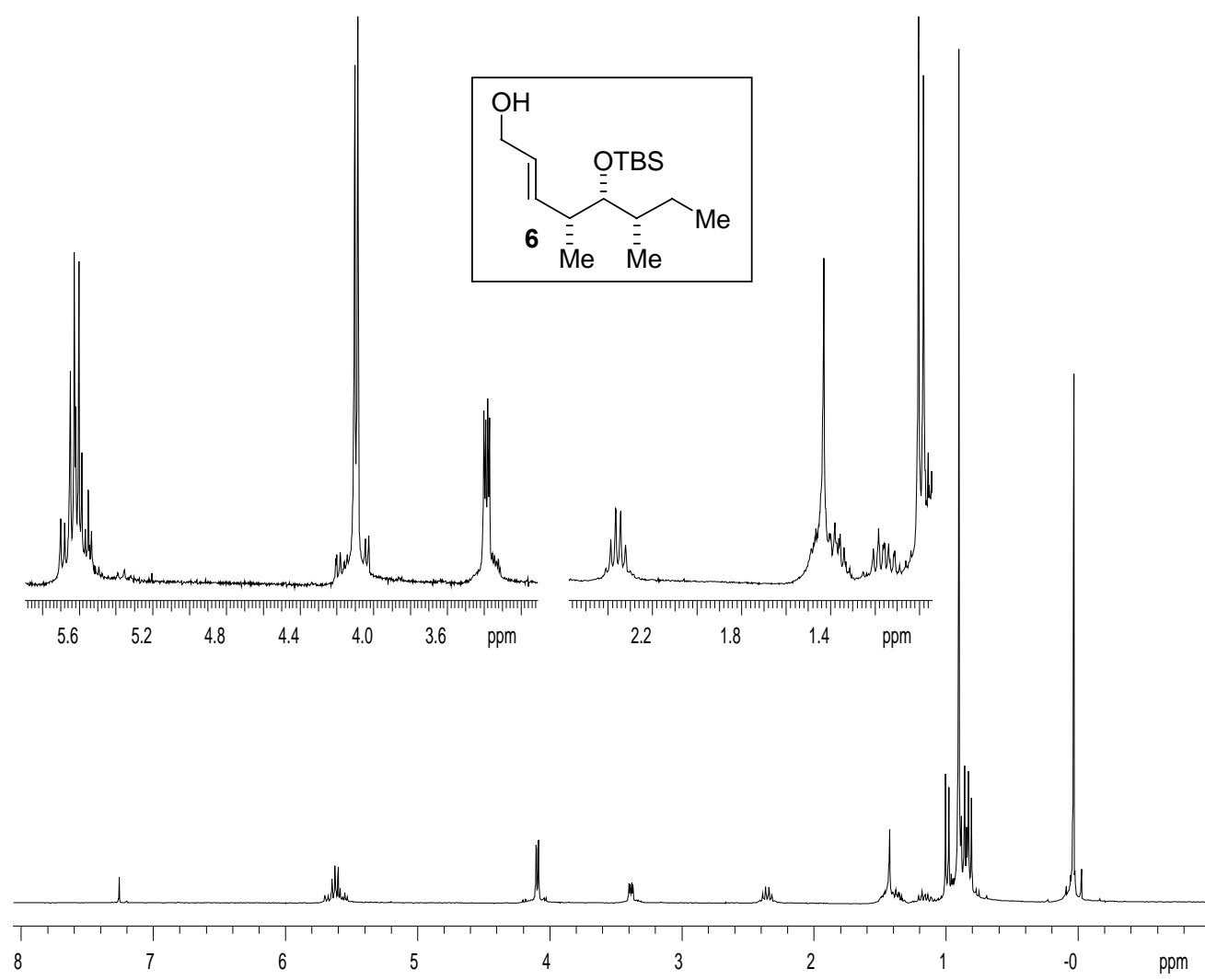

${ }^{1} \mathrm{H}$ NMR (300 MHz, $\mathrm{CDCl}_{3}$ ) - Allylic alcohol (6)

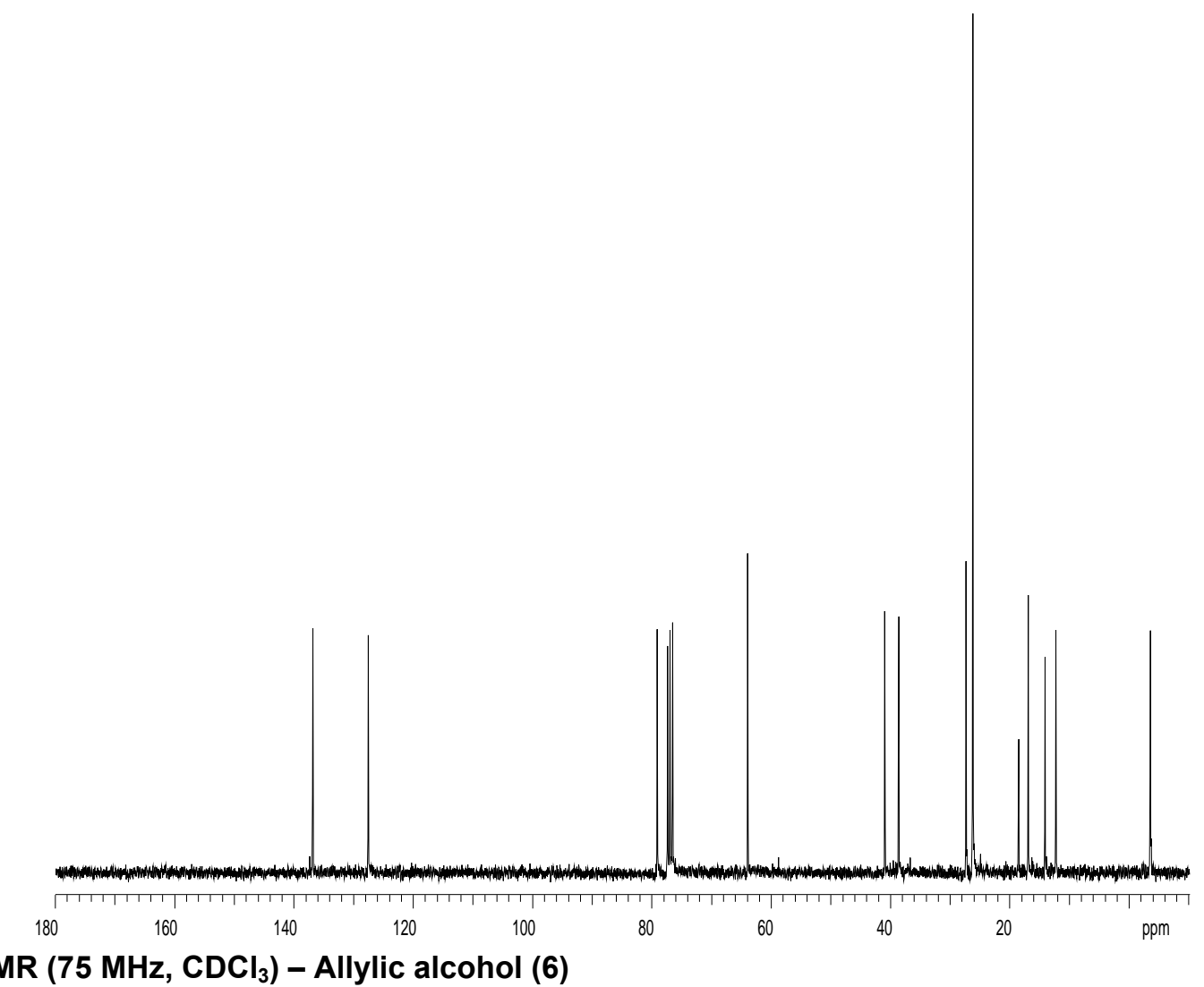

${ }^{13} \mathrm{C}$ NMR (75 MHz, $\mathrm{CDCl}_{3}$ ) - Allylic alcohol (6) 

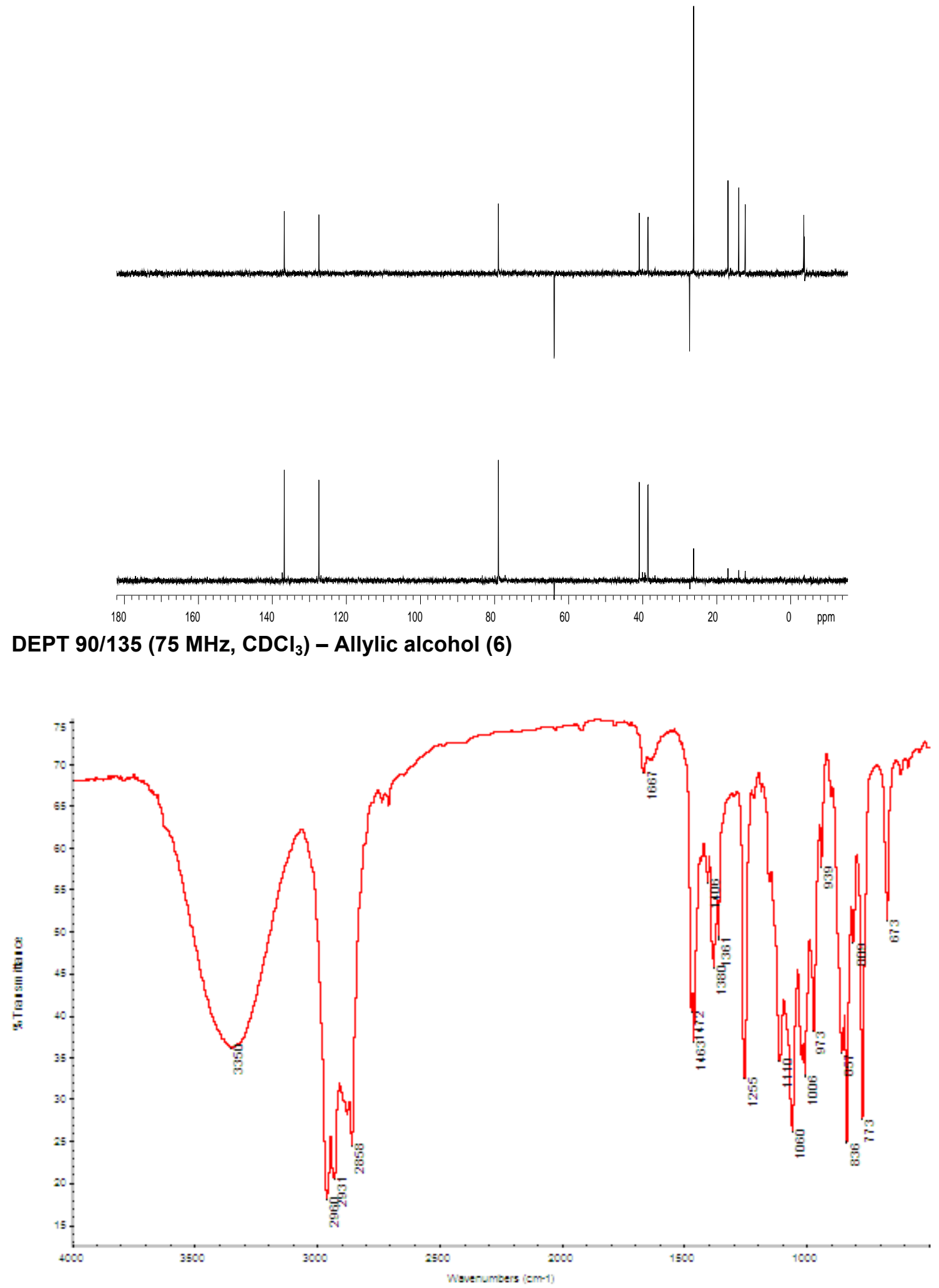

IR (film) - Allylic alcohol (6) 
SI-76

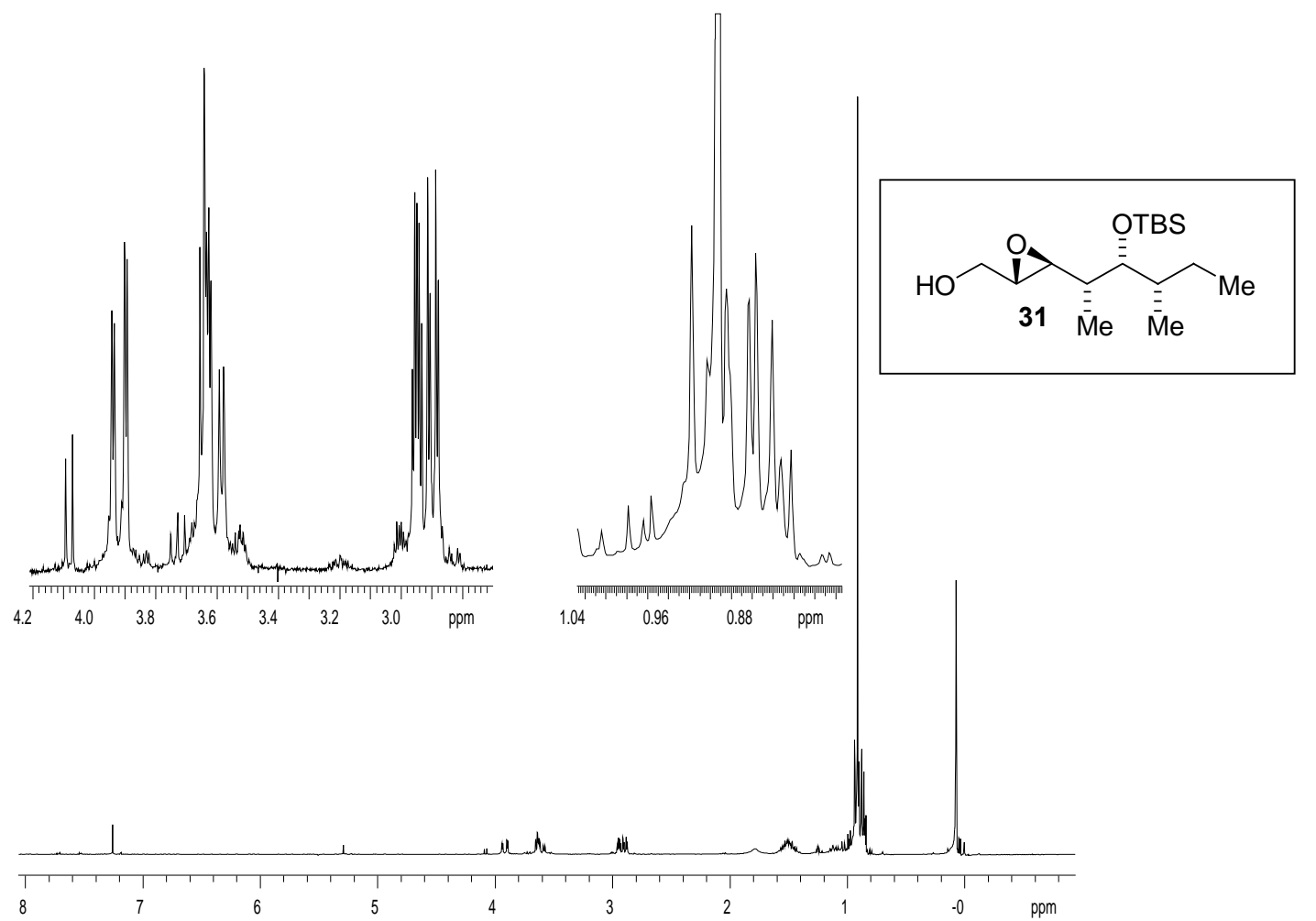

${ }^{1} \mathrm{H}$ NMR (300 MHz, $\mathrm{CDCl}_{3}$ ) - Epoxide (31)
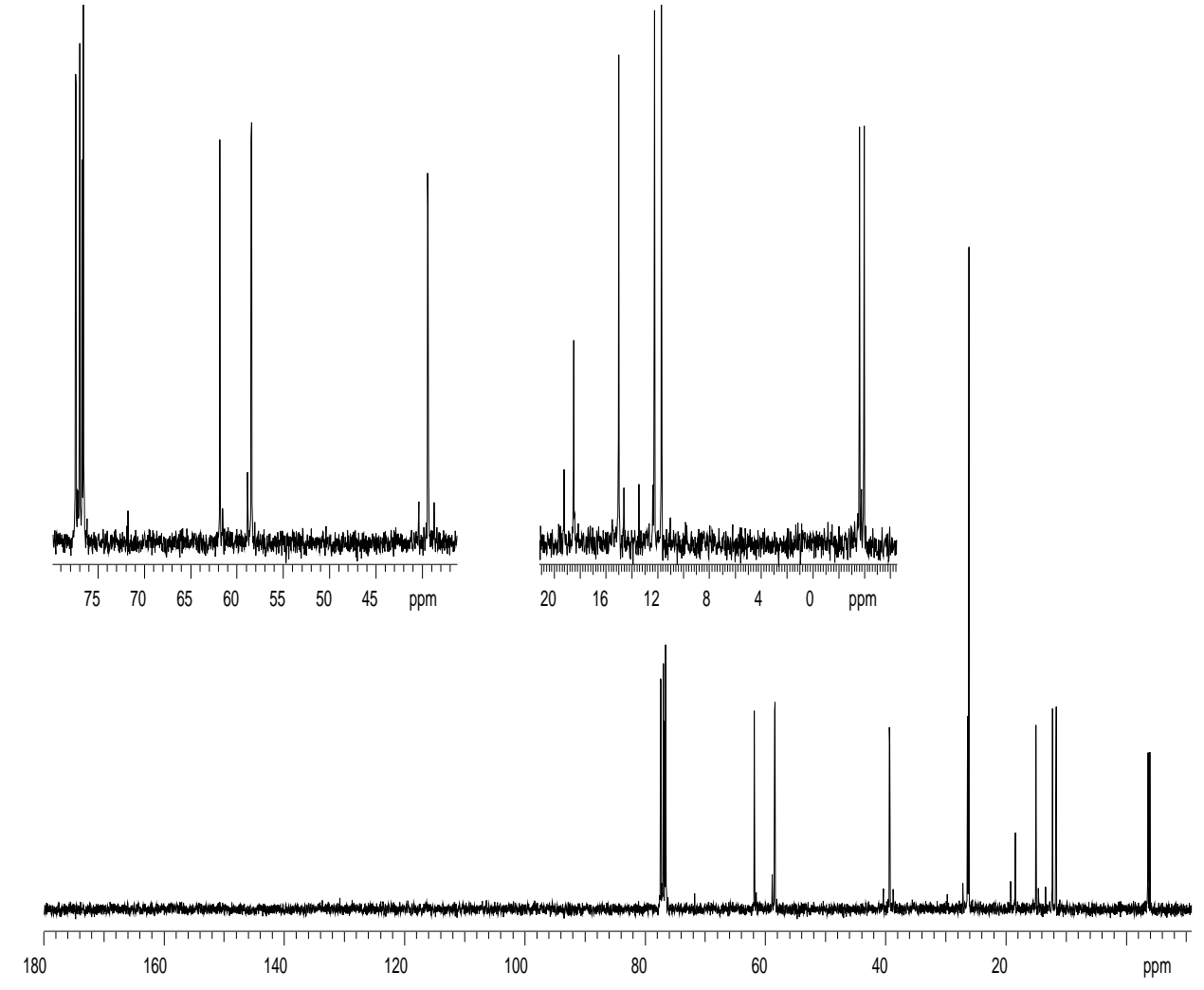

${ }^{13} \mathrm{C}$ NMR (75 MHz, $\mathrm{CDCl}_{3}$ ) - Epoxide (31) 

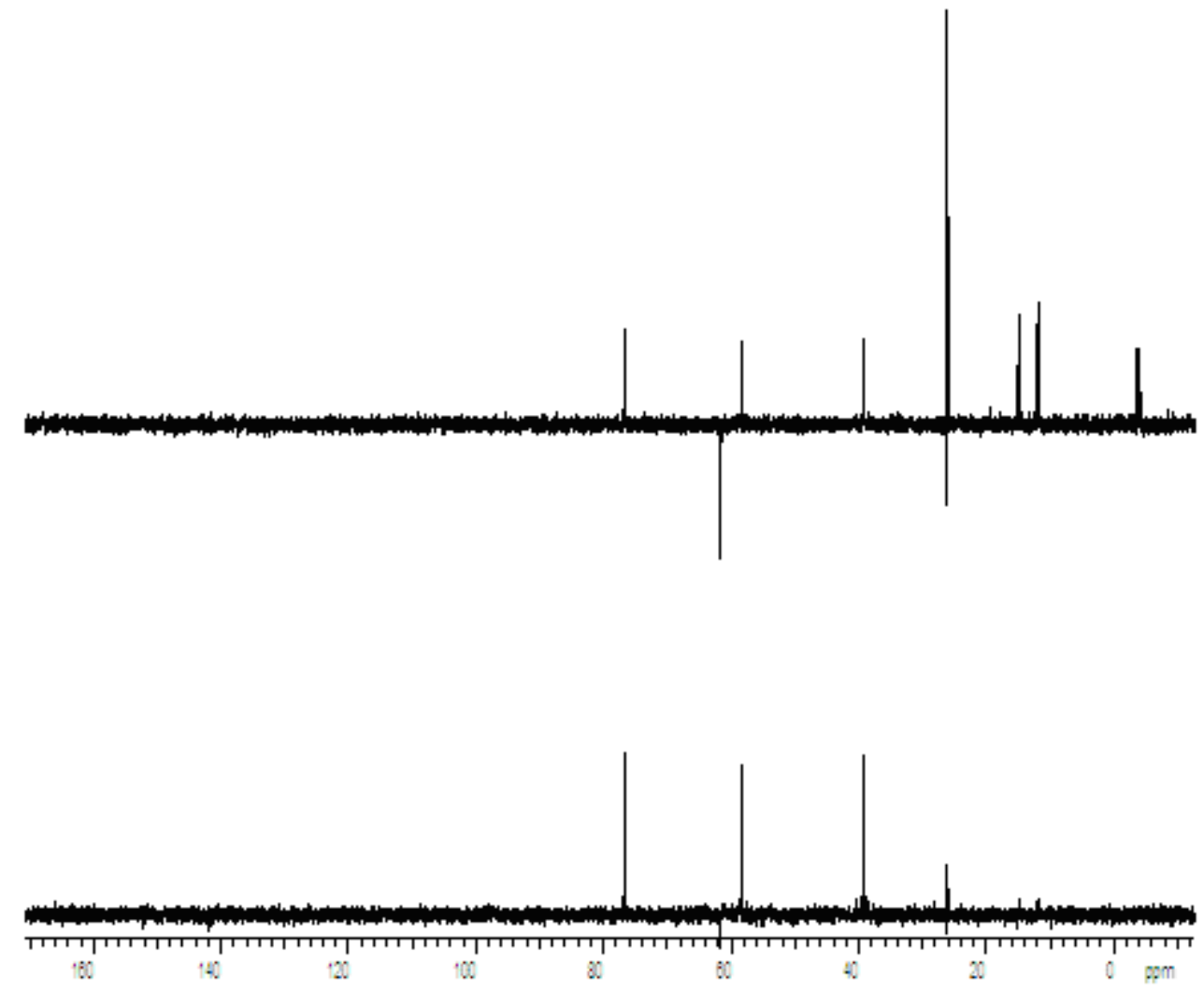

DEPT 90/135 (75 MHz, $\mathrm{CDCl}_{3}$ ) - Epoxide (31)

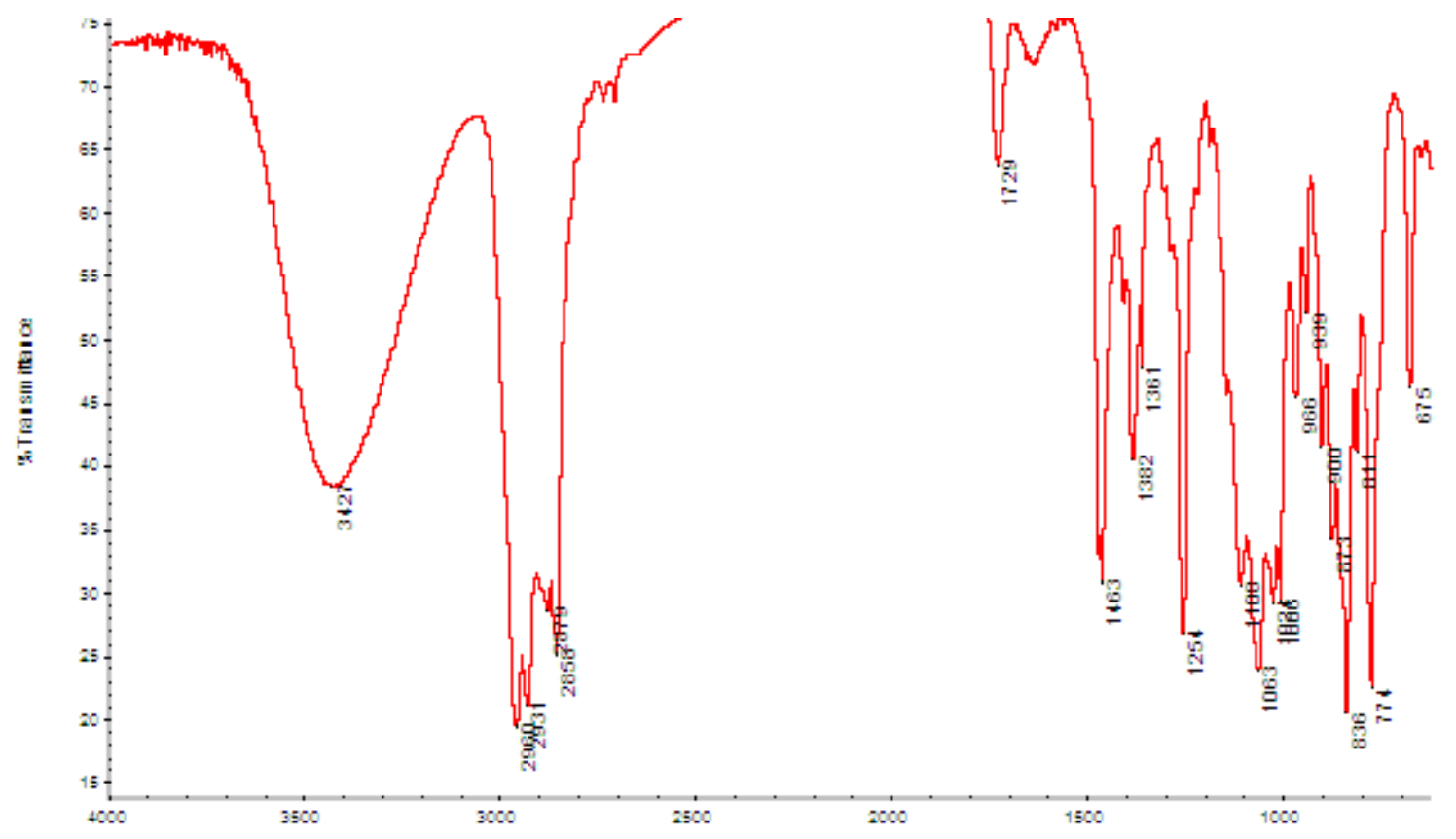

IR (film) - Epoxide (31) 


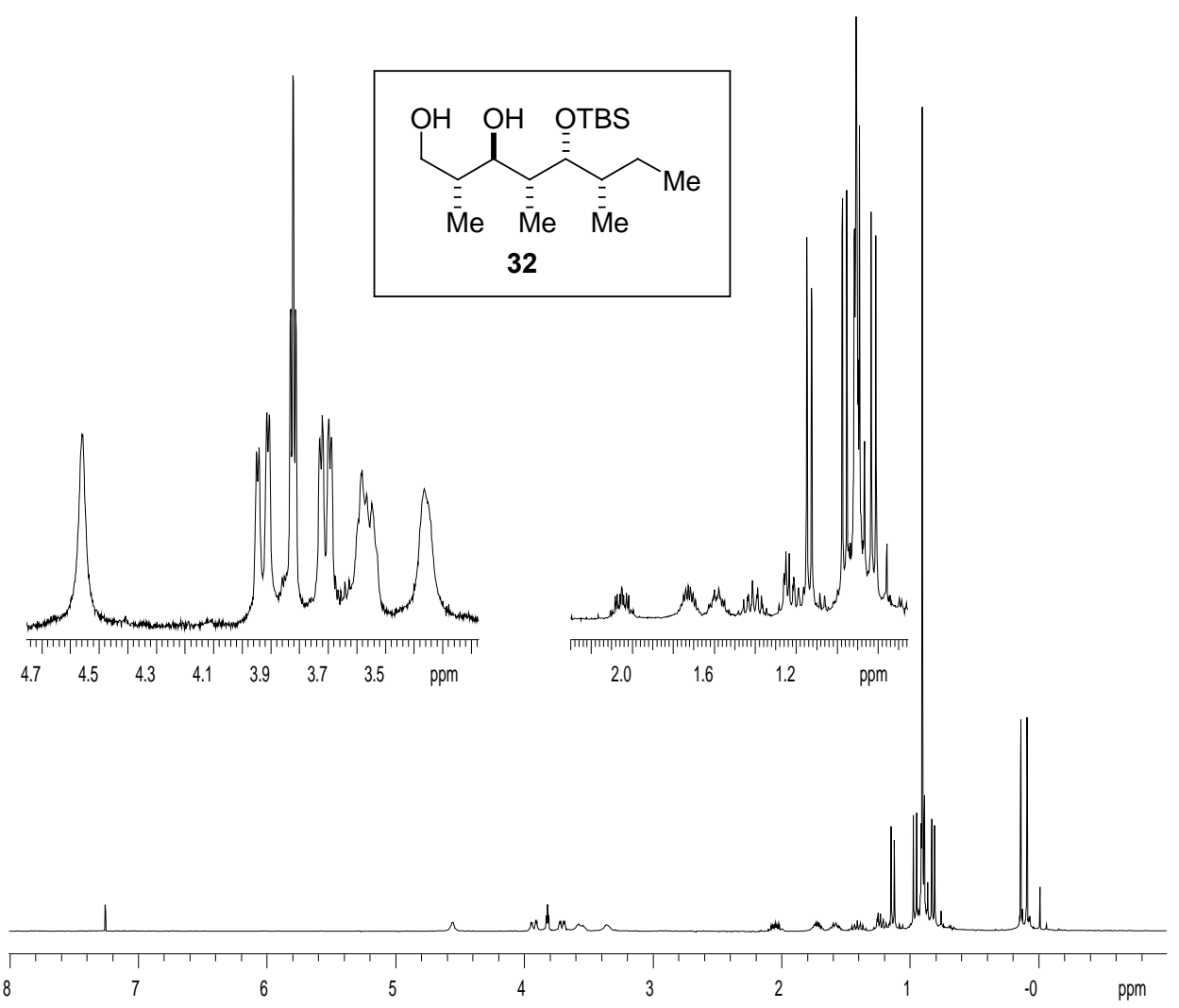

${ }^{1} \mathrm{H}$ NMR (300 MHz, $\left.\mathrm{CDCl}_{3}\right)$ - Diol (32)
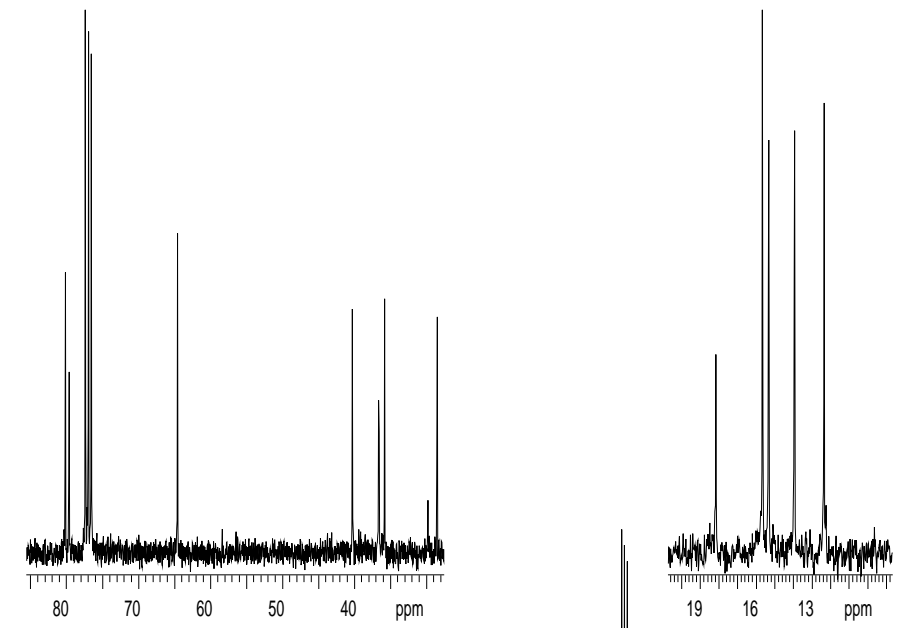

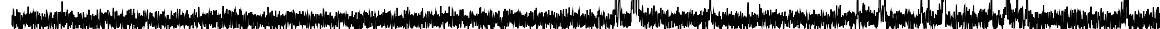

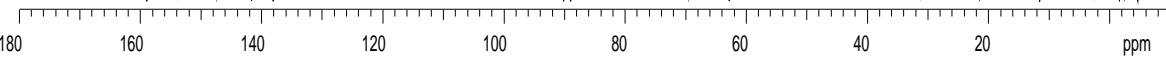

${ }^{13} \mathrm{C}$ NMR (75 MHz, $\mathrm{CDCl}_{3}$ ) - Diol (32) 

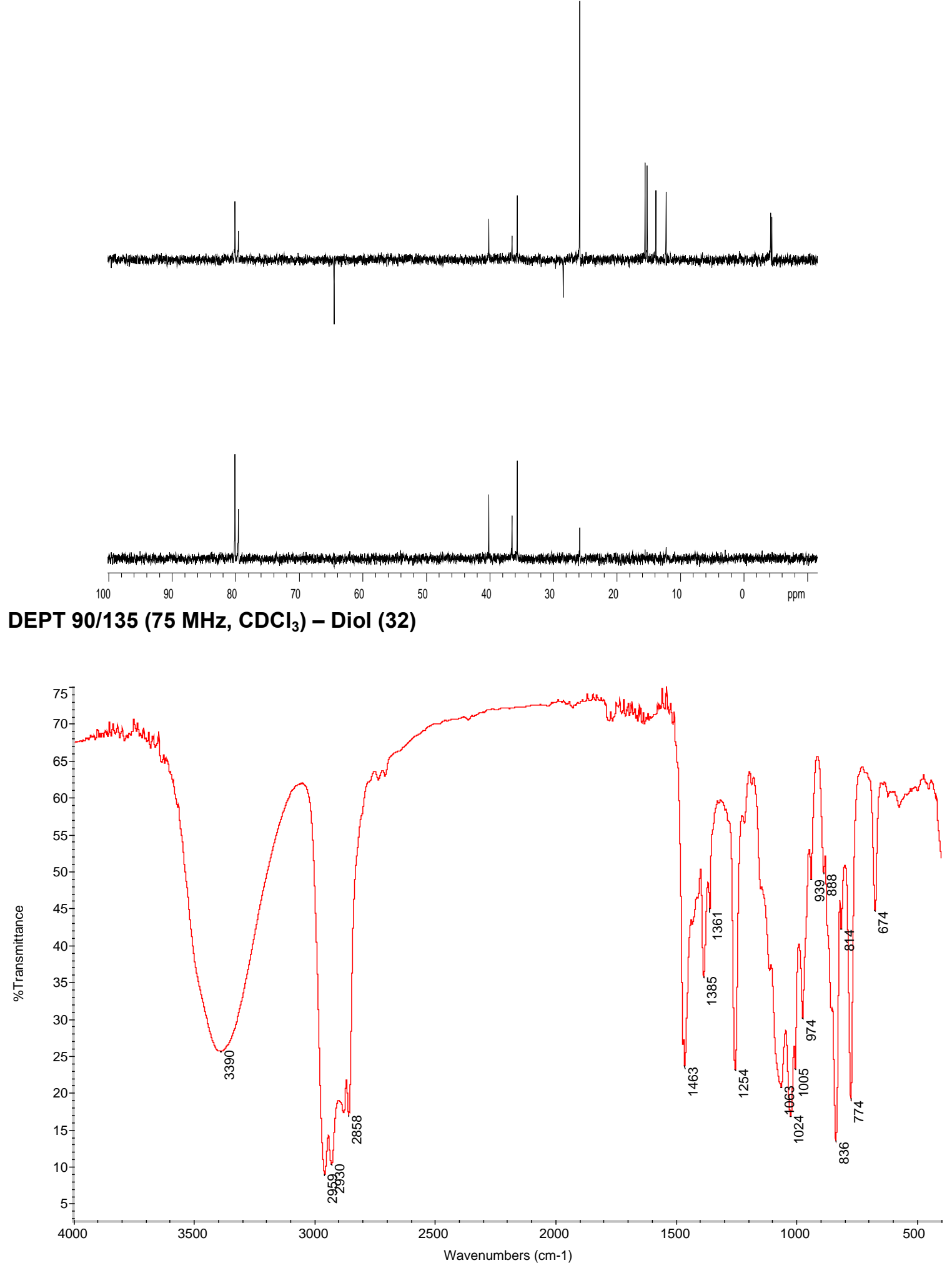

IR (film) - Diol (32) 

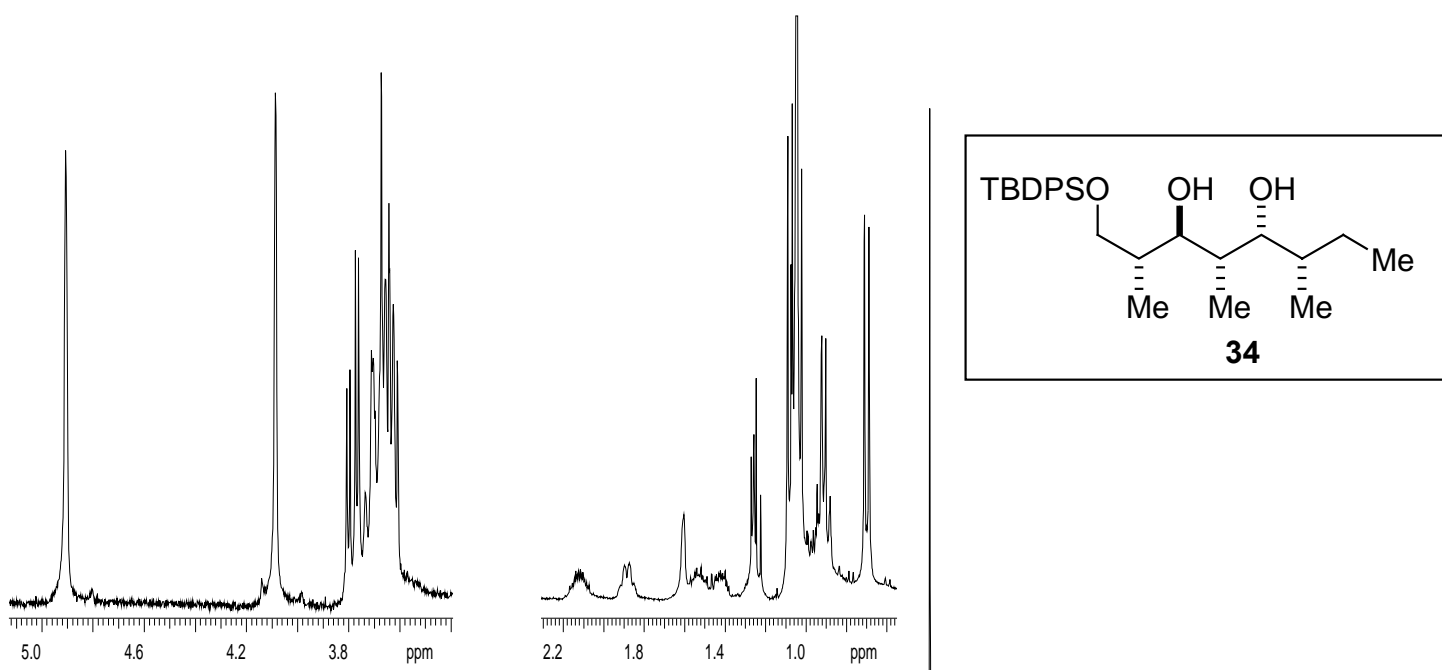

${ }^{1} \mathrm{H}$ NMR (300 MHz, $\mathrm{CDCl}_{3}$ ) - Diol (34)
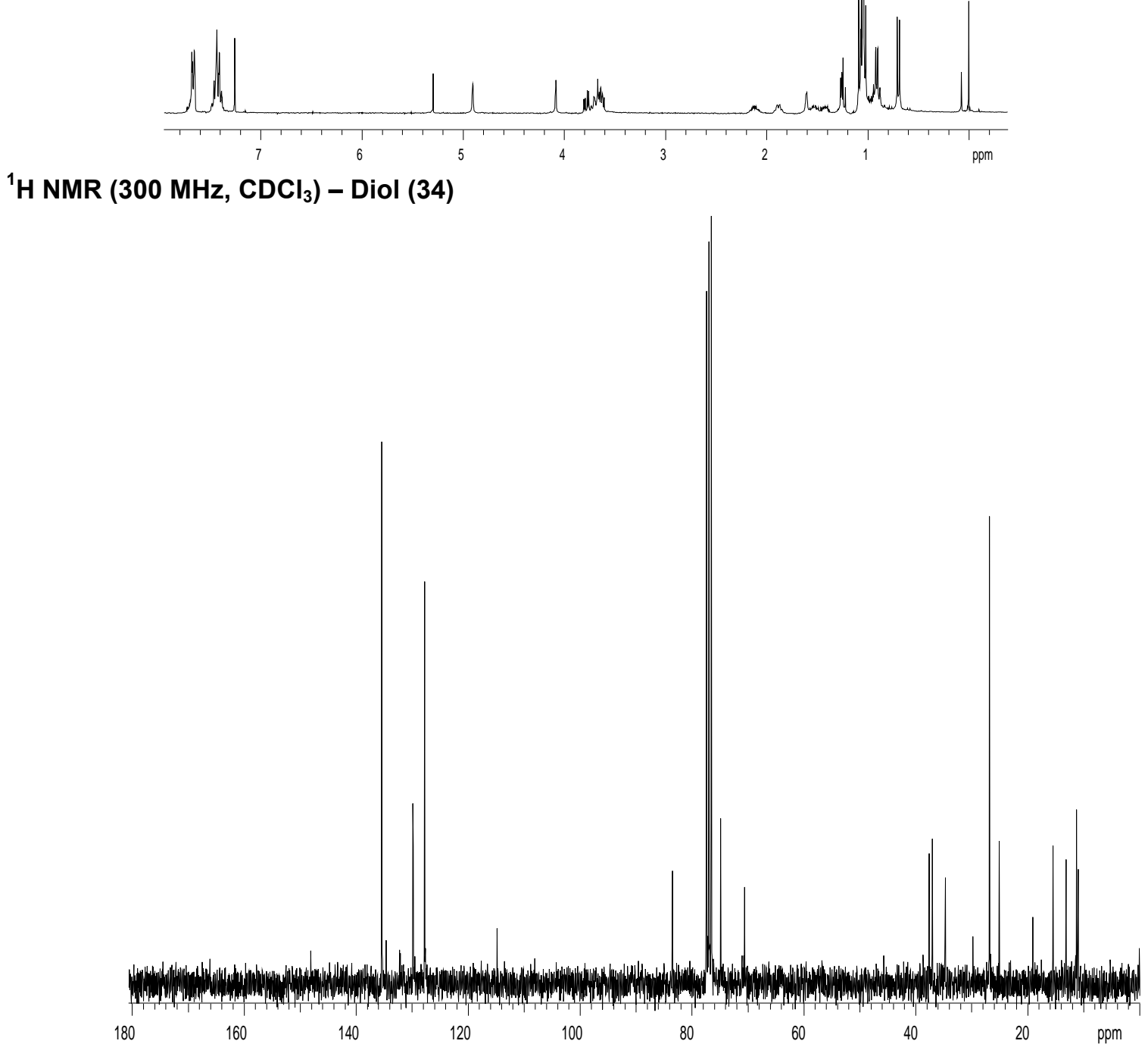

${ }^{13} \mathrm{C}$ NMR (75 MHz, $\mathrm{CDCl}_{3}$ ) - Diol (34) 

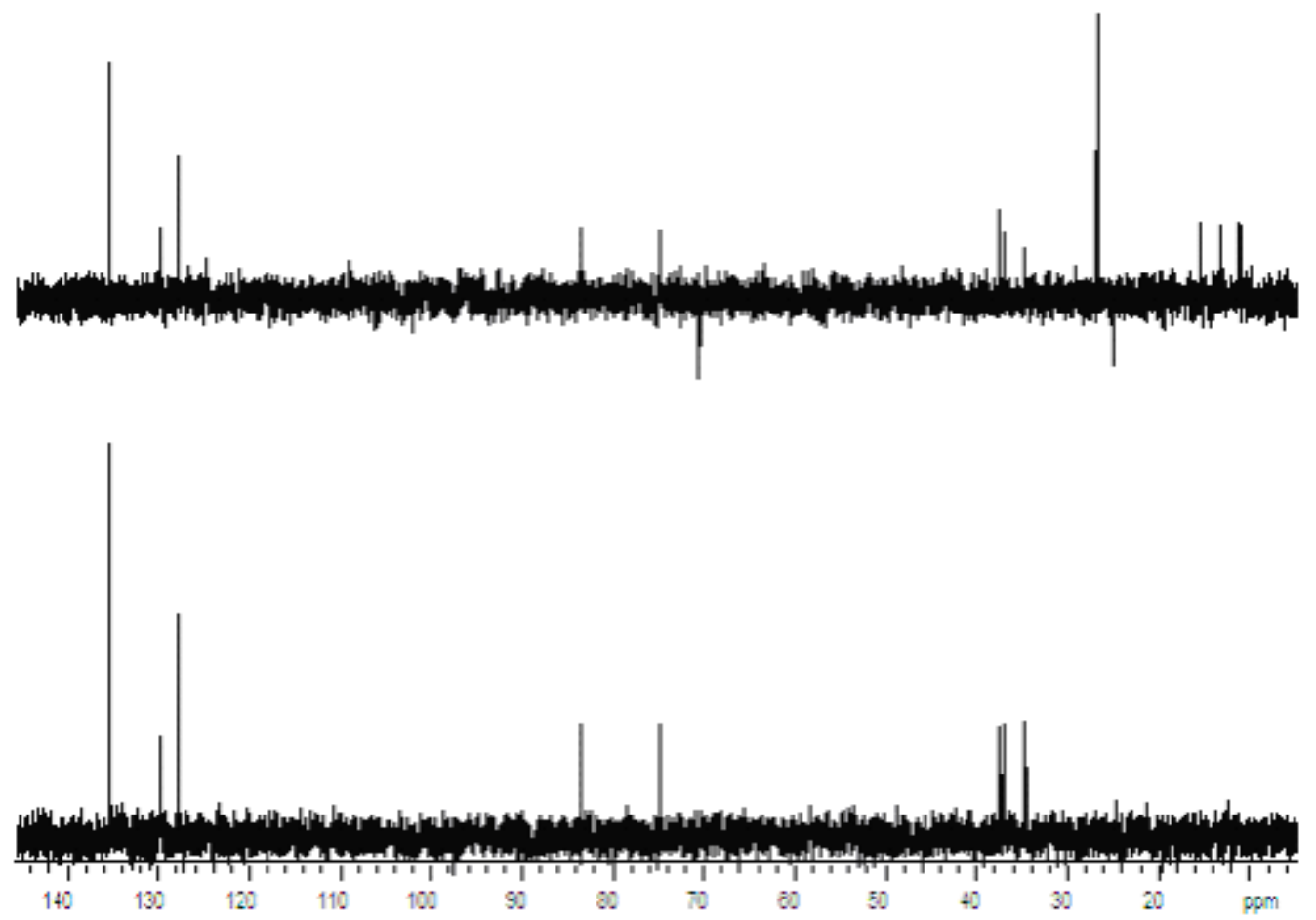

DEPT 90/135 (75 MHz, $\mathrm{CDCl}_{3}$ ) - Diol (34)
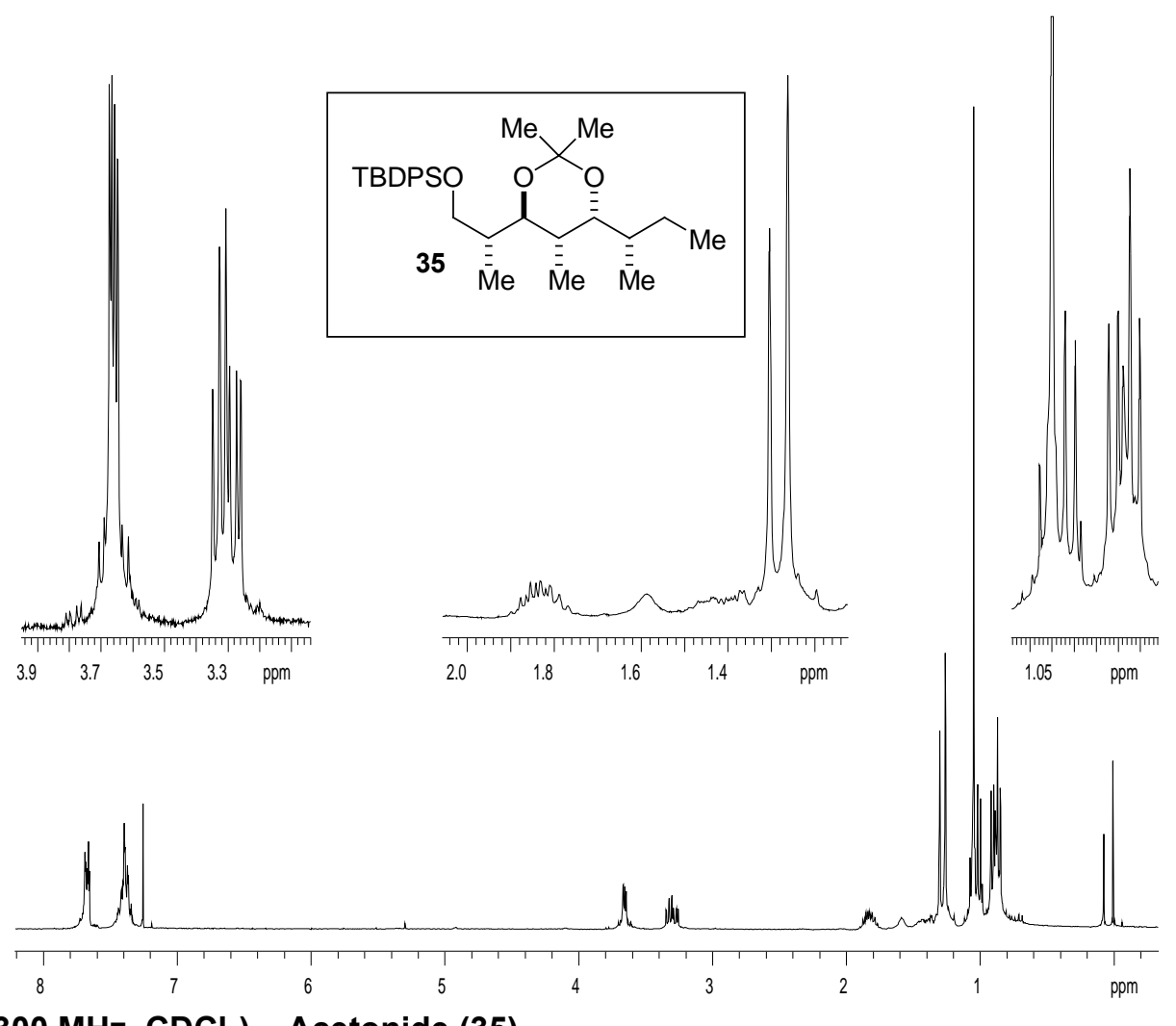

${ }^{1} \mathrm{H}$ NMR (300 MHz, $\mathrm{CDCl}_{3}$ ) - Acetonide (35) 


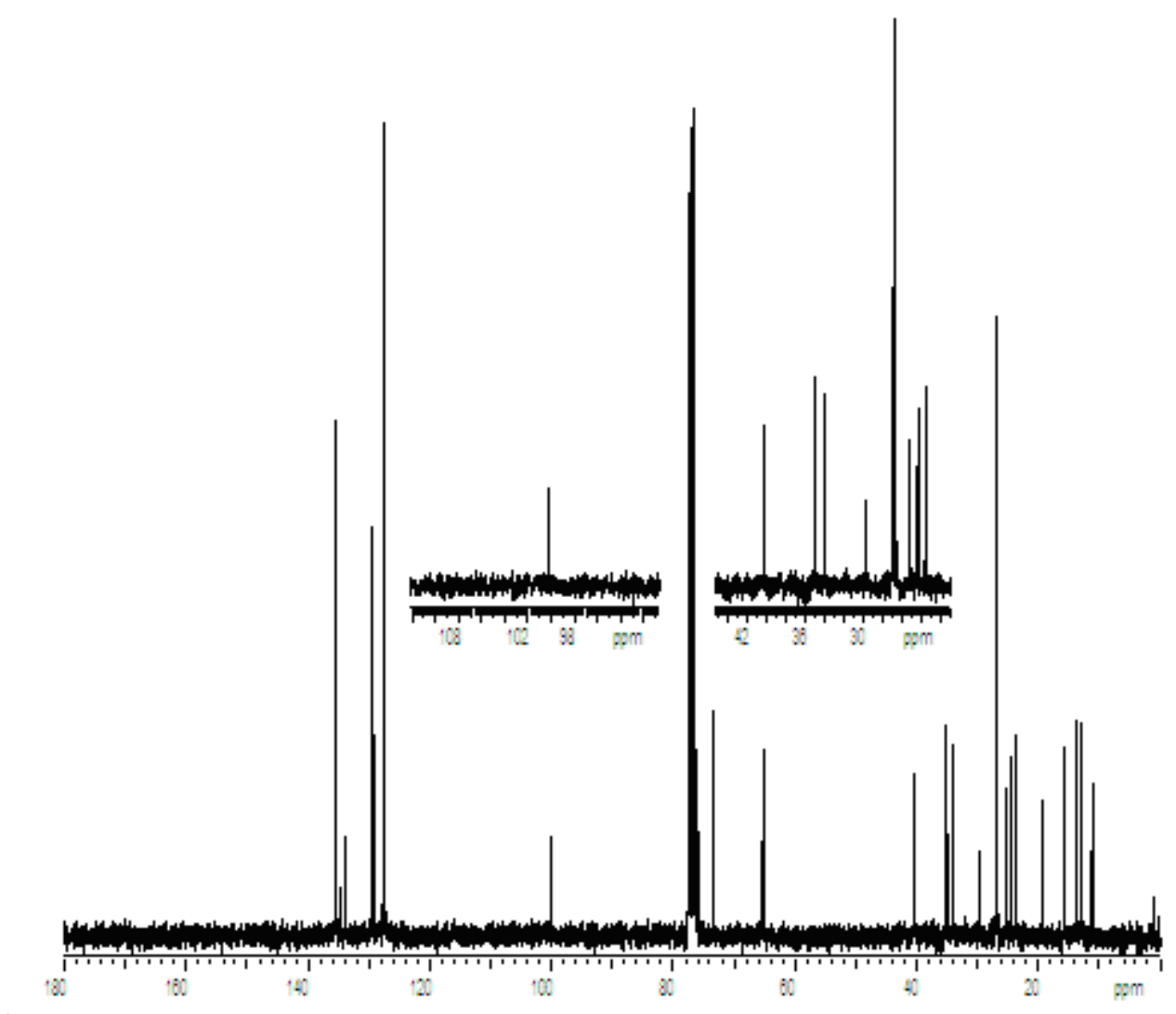

${ }^{13} \mathrm{C}$ NMR (75 MHz, $\mathrm{CDCl}_{3}$ ) - Acetonide (35)

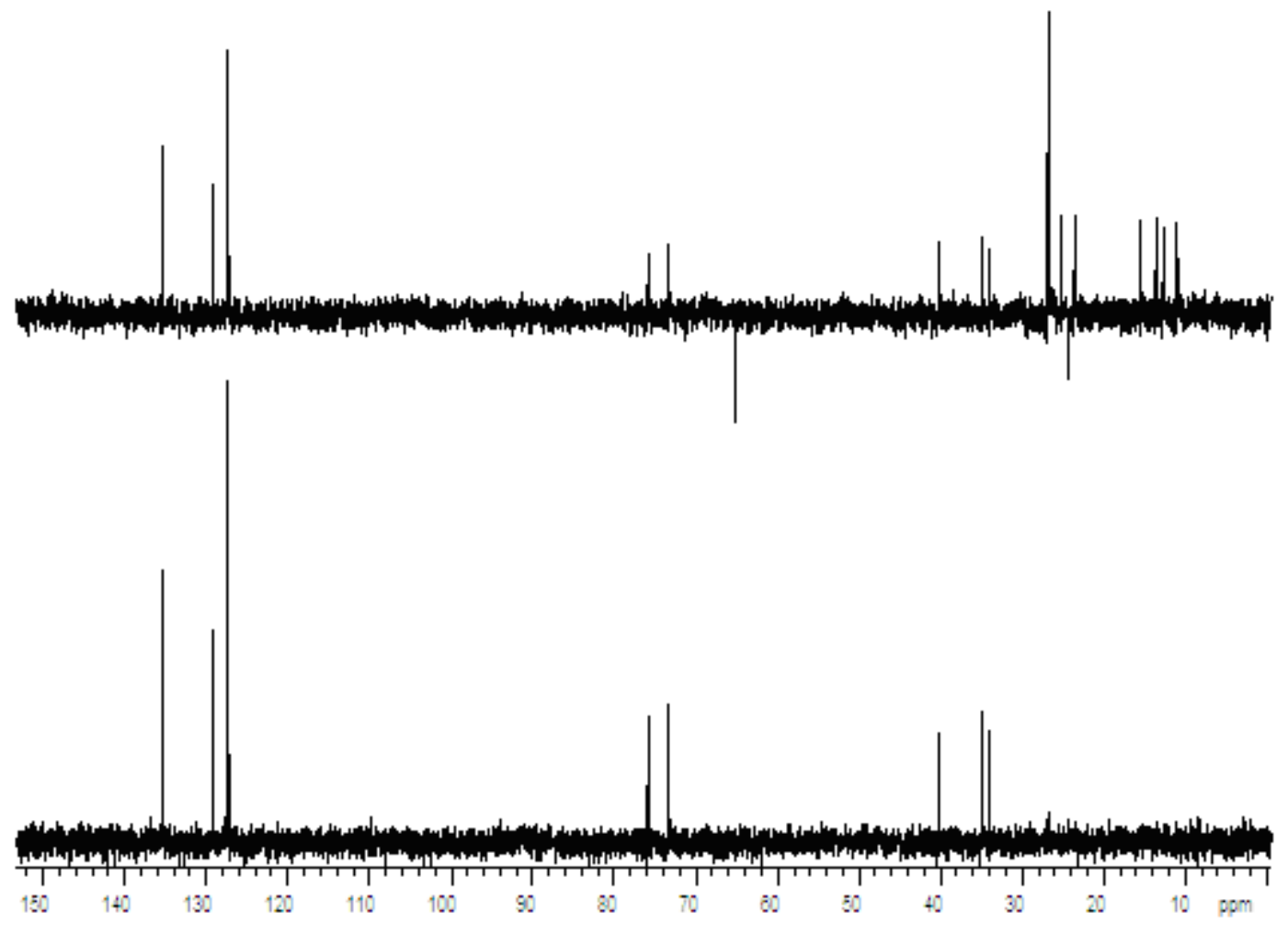

DEPT 90/135 (75 MHz, $\mathrm{CDCl}_{3}$ ) - Acetonide (35) 


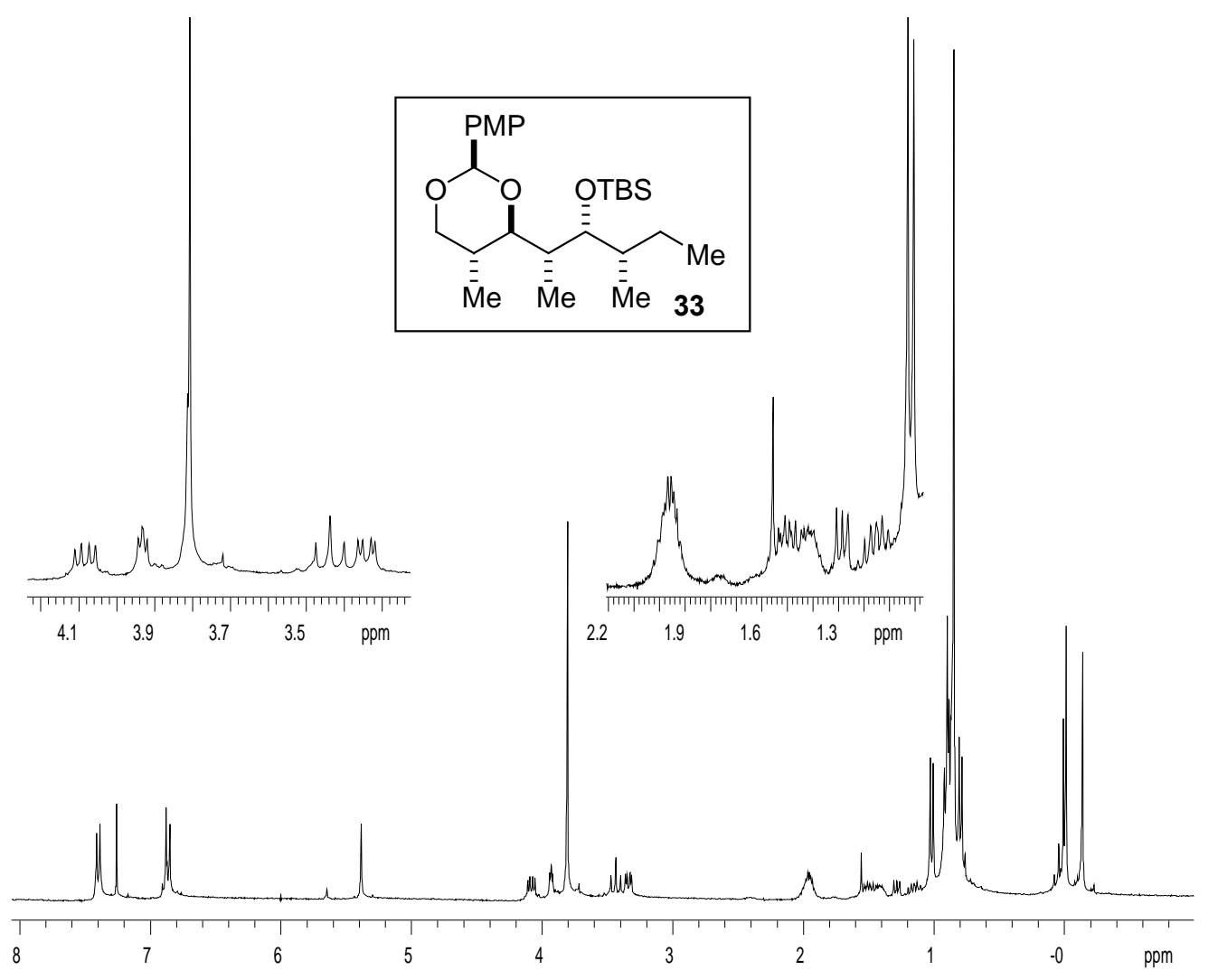

${ }^{1} \mathrm{H}$ NMR (300 MHz, $\left.\mathrm{CDCl}_{3}\right)$ - Acetal (33)
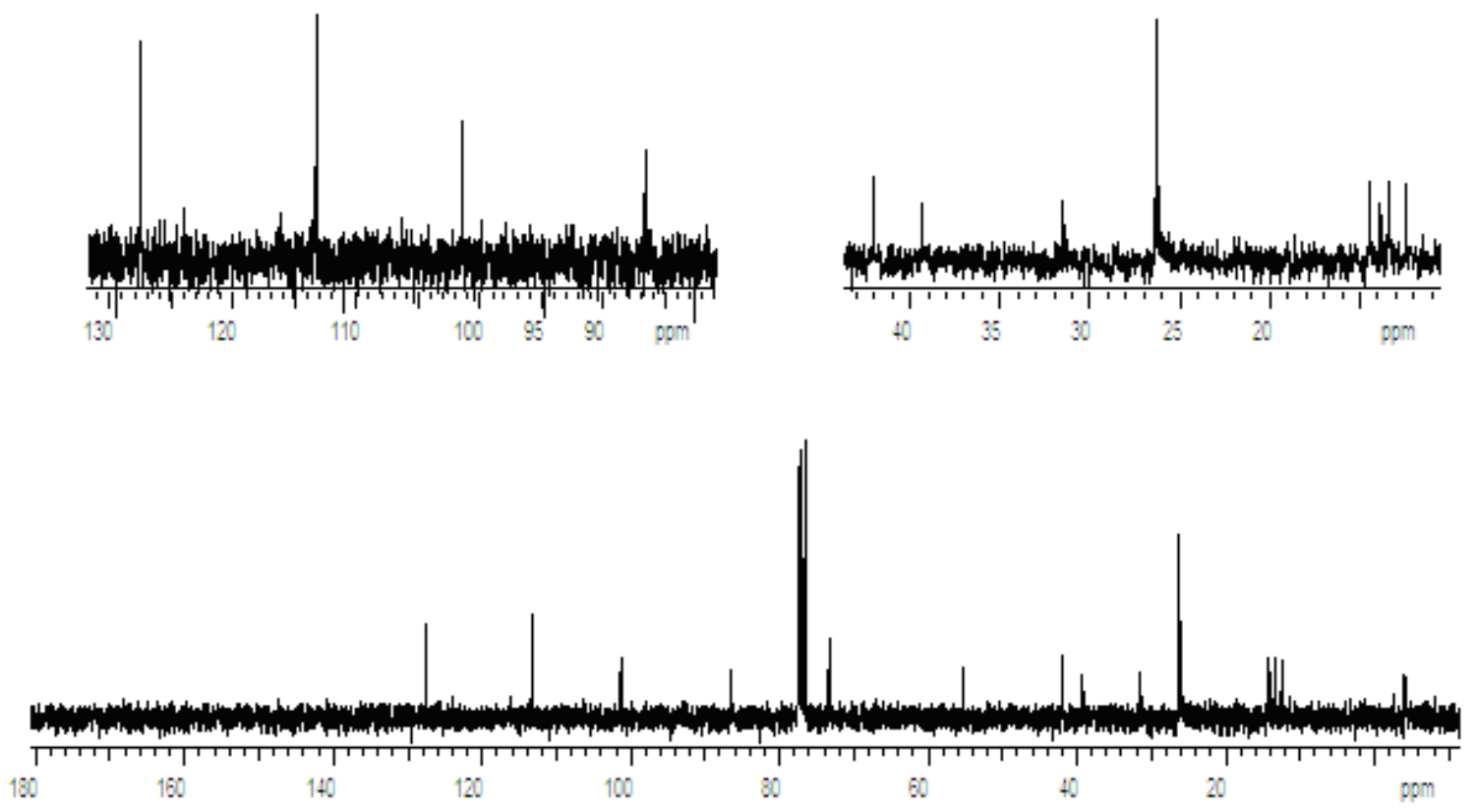

${ }^{13} \mathrm{C}$ NMR (75 MHz, $\mathrm{CDCl}_{3}$ ) - Acetal (33) 


\section{SI-84}
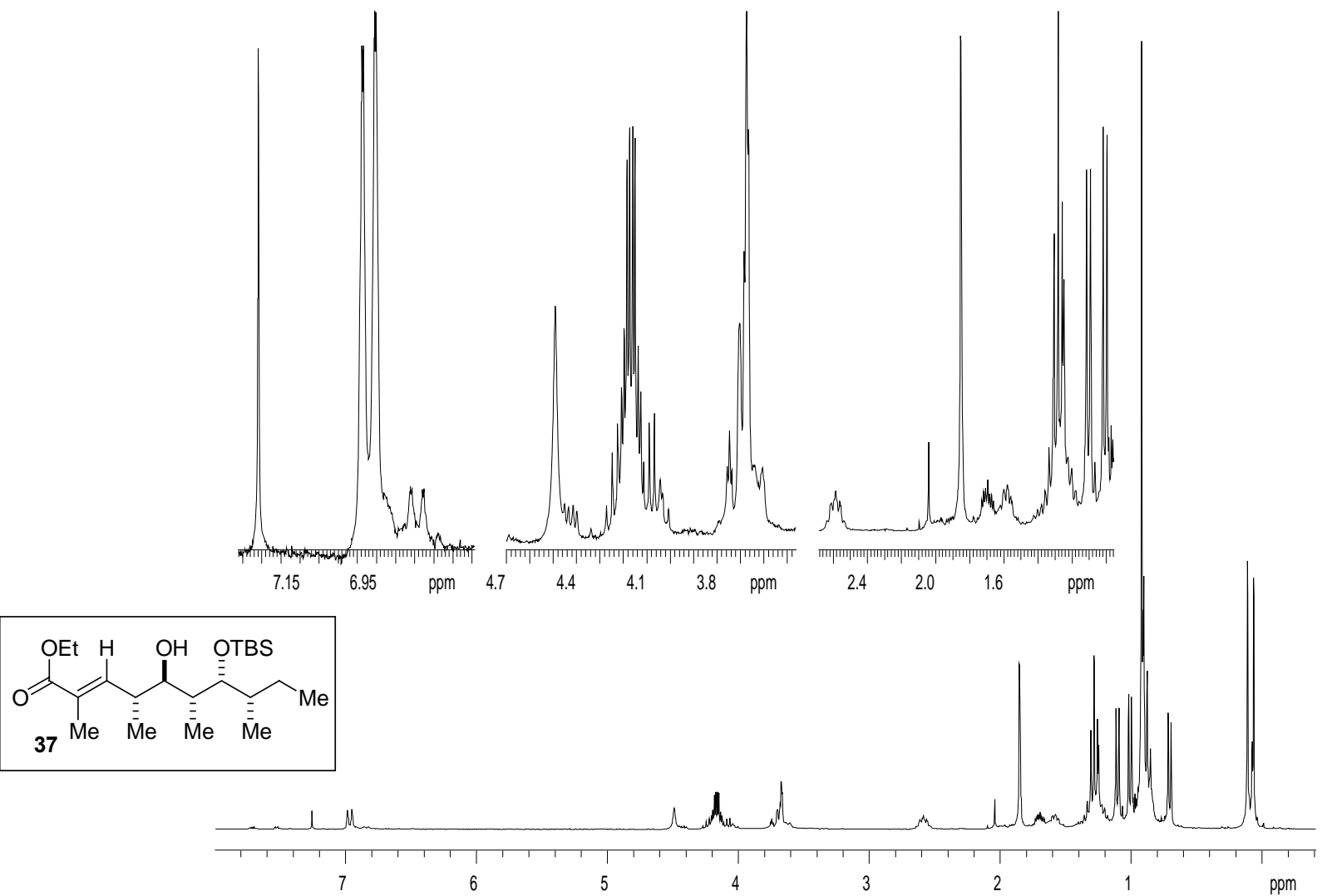

${ }^{1} \mathrm{H}$ NMR (300 MHz, $\left.\mathrm{CDCl}_{3}\right)$ - Unsaturated ester (37)

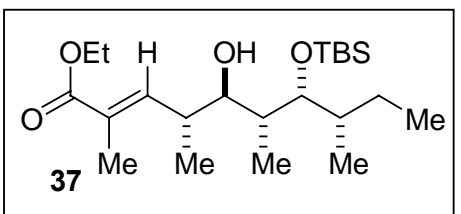

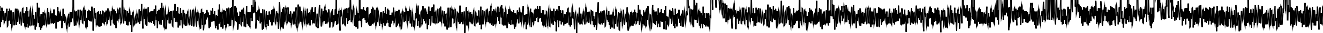

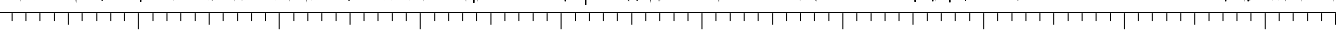

160

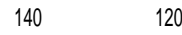

100

80

60

40

20

ppm

${ }^{13} \mathrm{C}$ NMR (75 $\mathrm{MHz}, \mathrm{CDCl}_{3}$ ) - Unsaturated ester (37) 

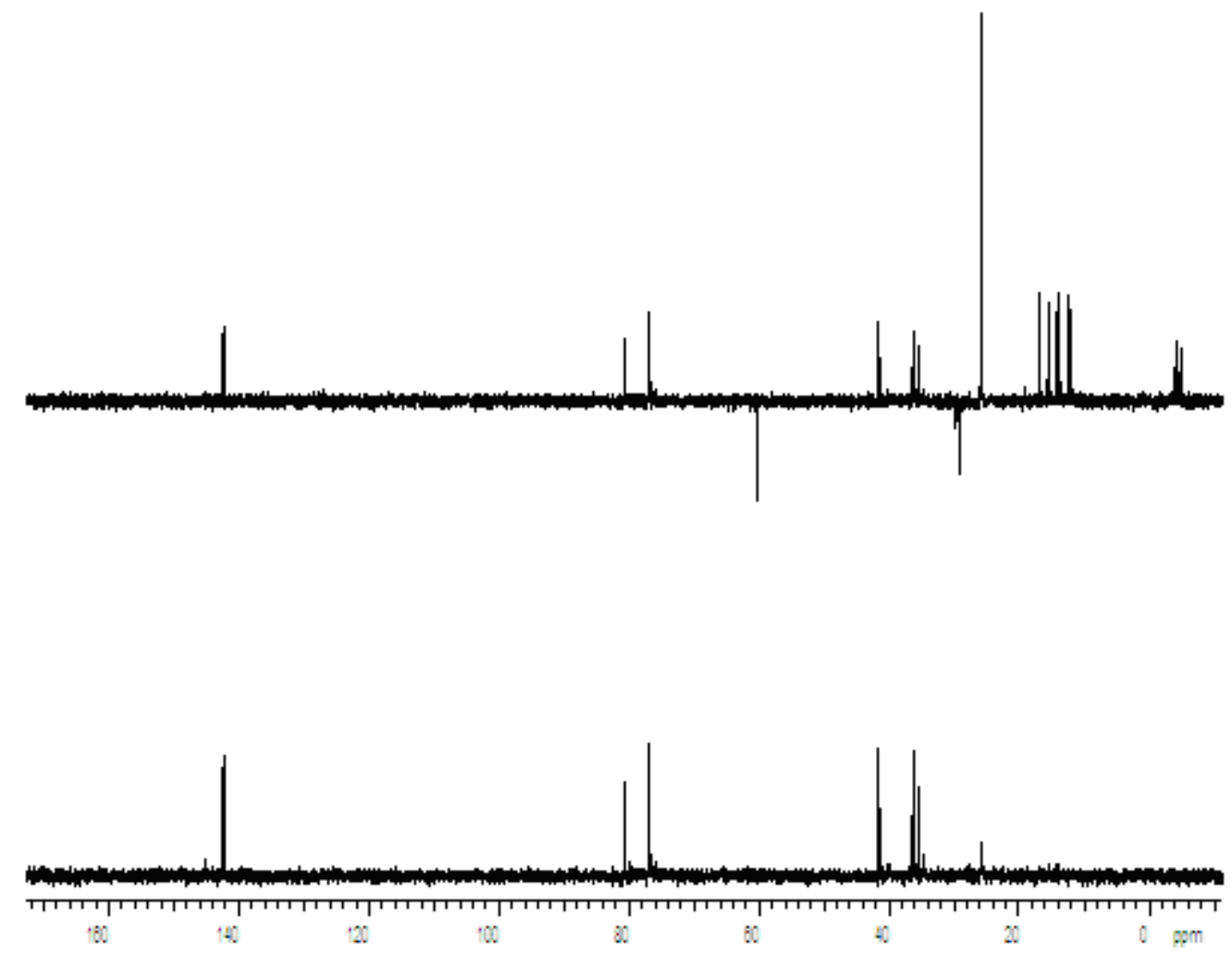

DEPT 90/135 (75 MHz, $\mathrm{CDCl}_{3}$ ) - Unsaturated ester (37)

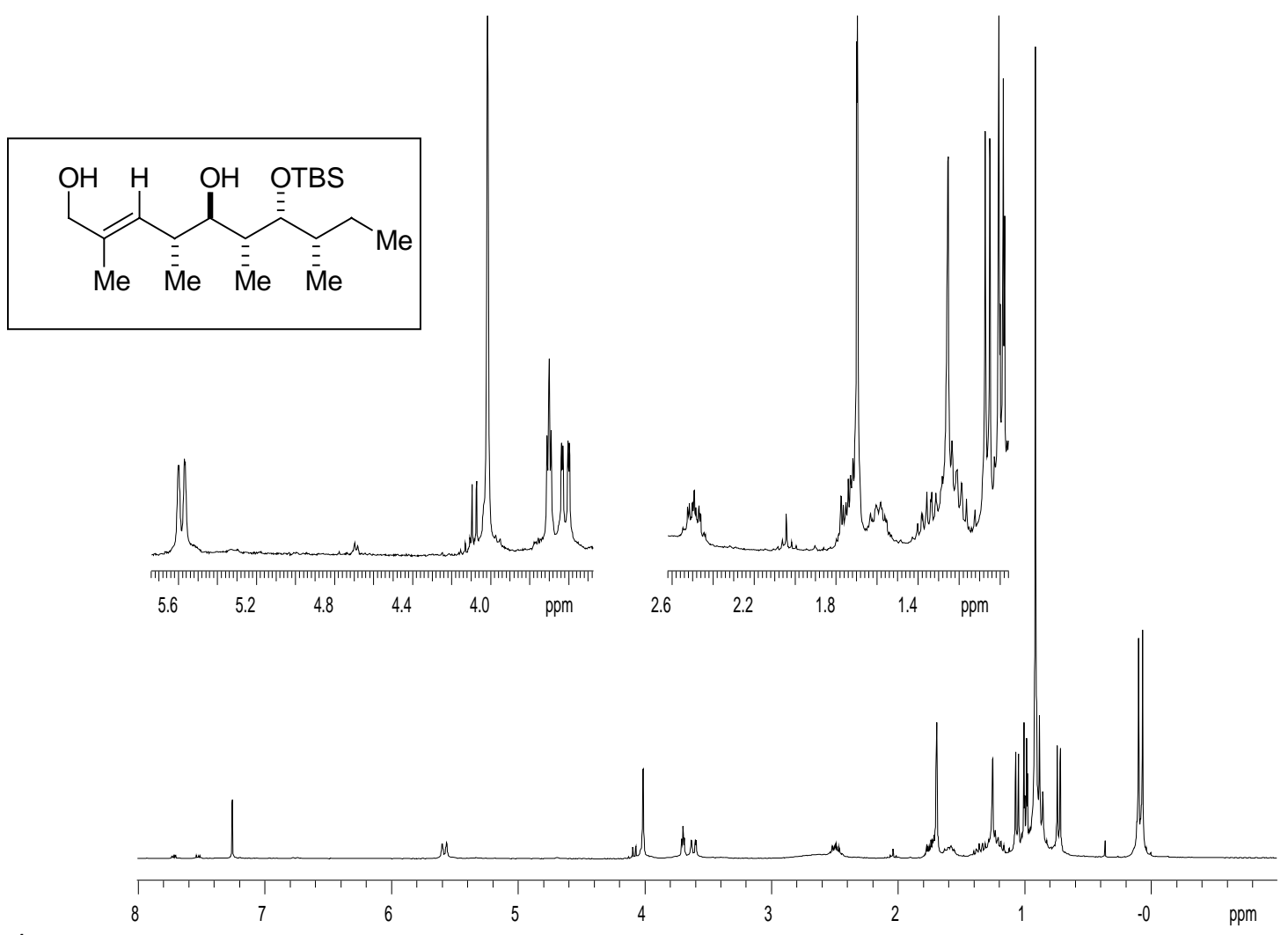

${ }^{1} \mathrm{H}$ NMR (300 MHz, $\mathrm{CDCl}_{3}$ ) - Allylic alcohol from (37) 


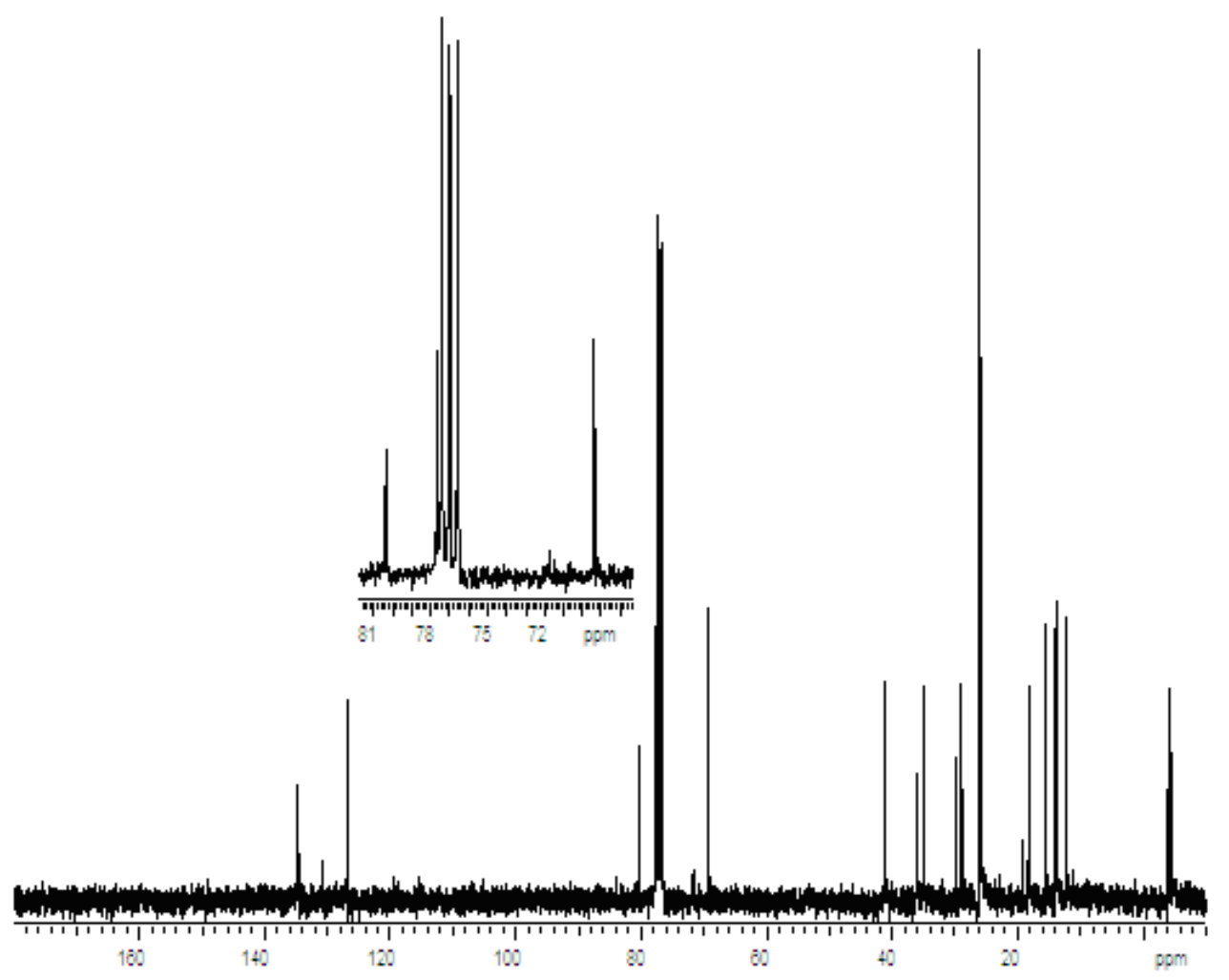

${ }^{13} \mathrm{C}$ NMR (75 MHz, $\mathrm{CDCl}_{3}$ ) - Allylic alcohol from (37)
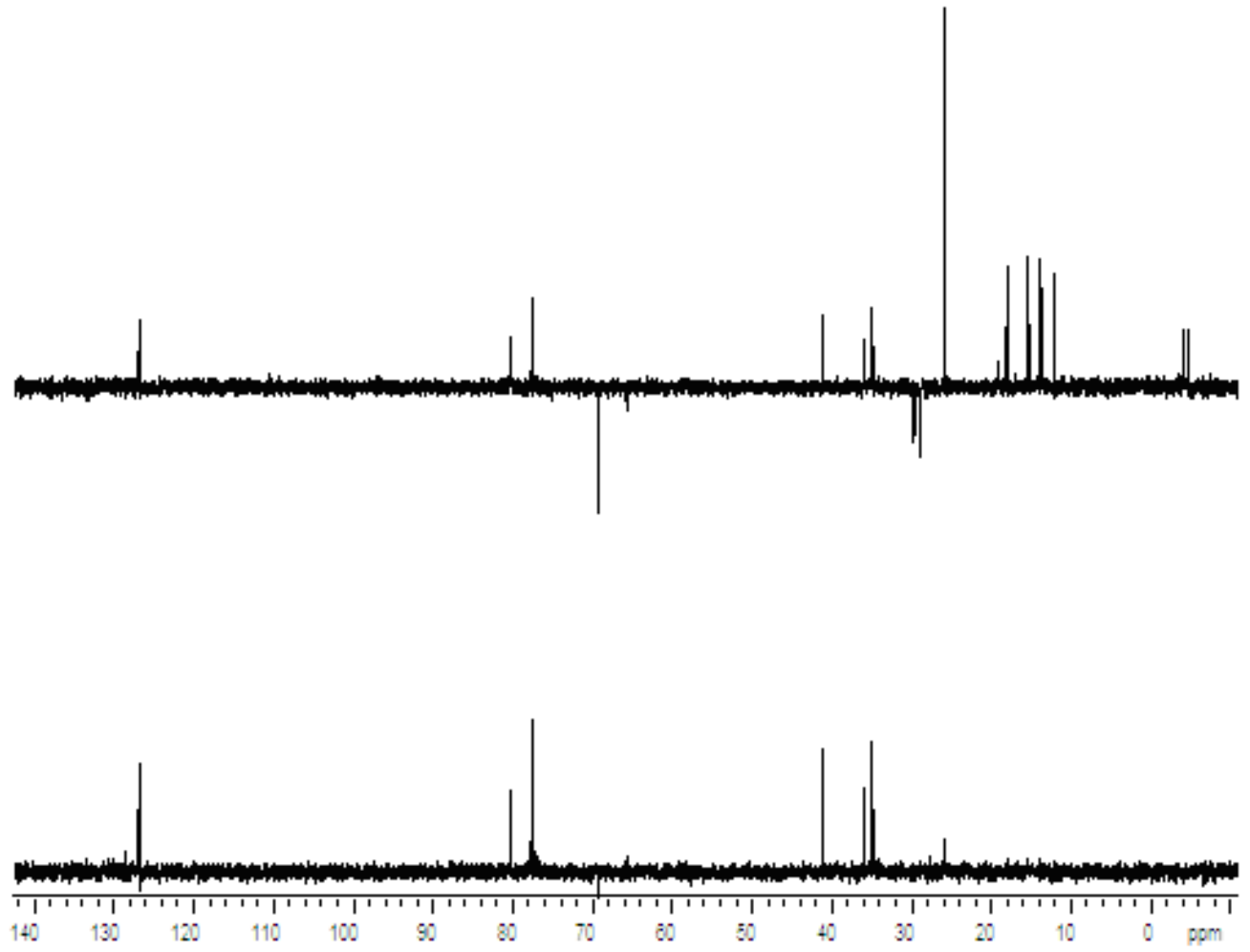

DEPT 90/135 (75 MHz, $\mathrm{CDCl}_{3}$ ) - Allylic alcohol from (37) 

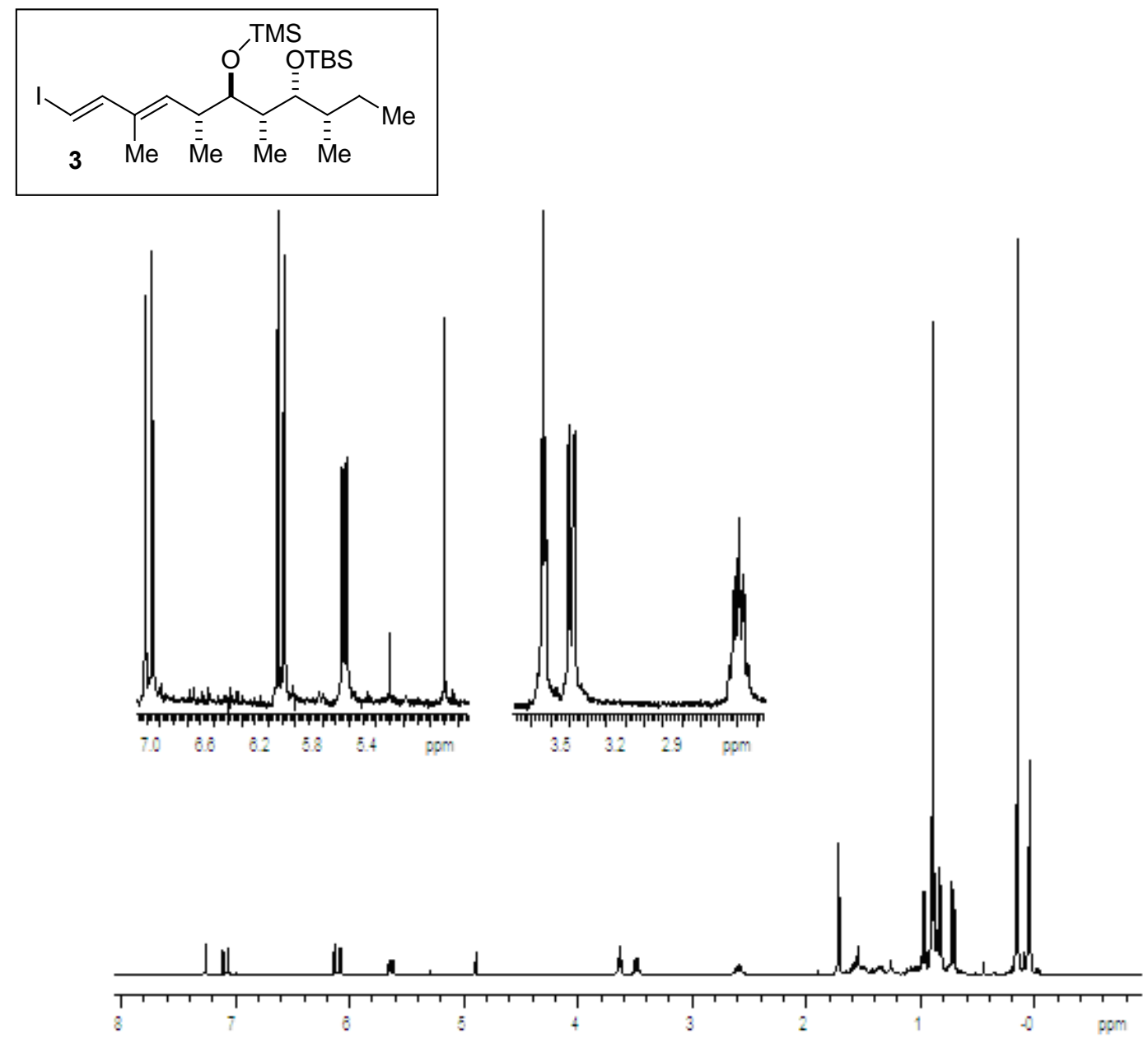

${ }^{1} \mathrm{H}$ NMR (300 MHz, $\left.\mathrm{CDCl}_{3}\right)$ - (E)-Vinyl iodide (3) 
Wat

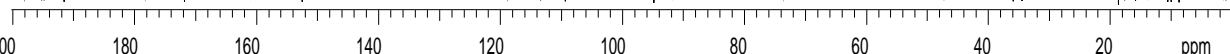

${ }^{13} \mathrm{C}$ NMR (75 $\left.\mathrm{MHz}, \mathrm{CDCl}_{3}\right)-(E)-V i n y l$ iodide (3)
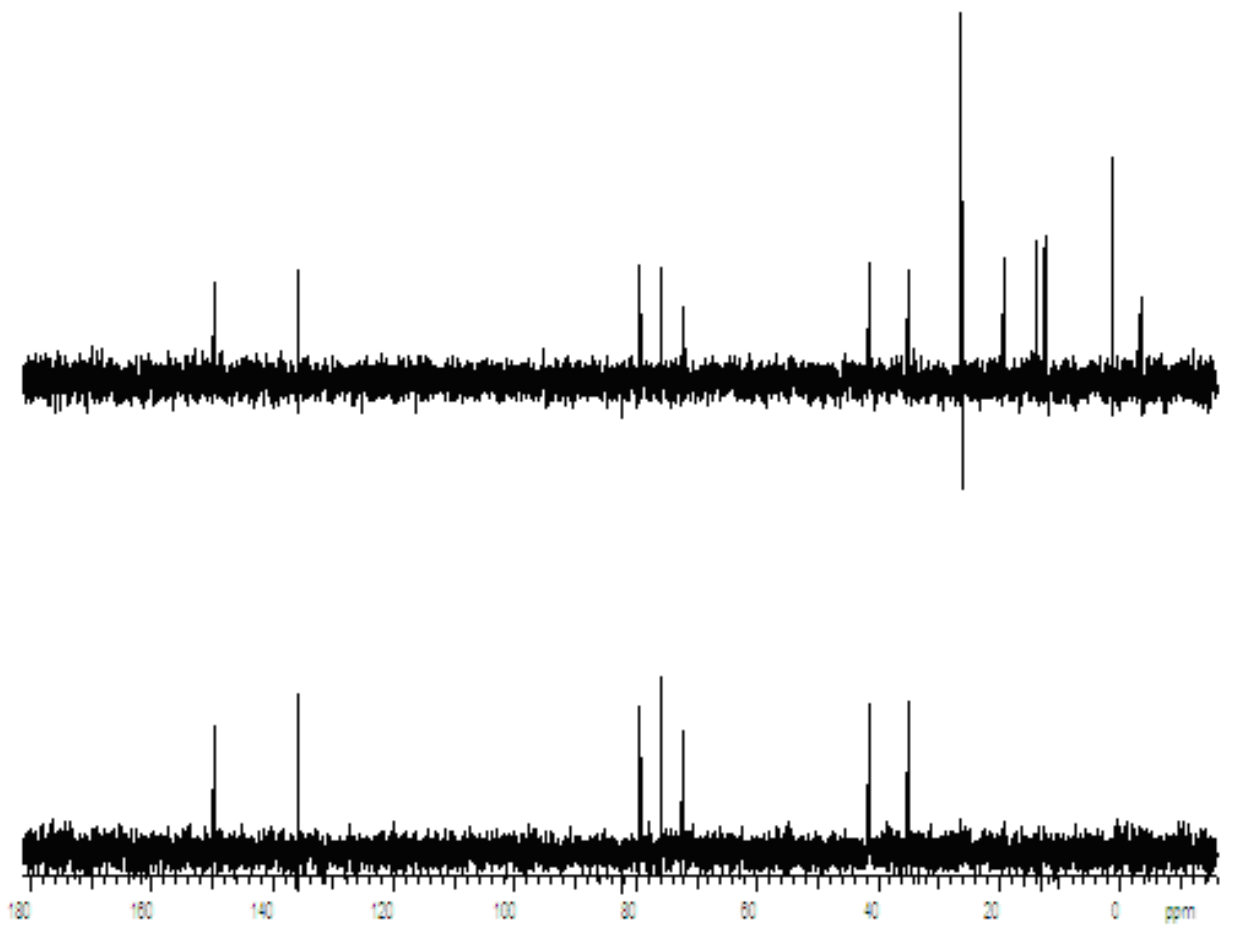

DEPT 90/135 (75 MHz, $\left.\mathrm{CDCl}_{3}\right)-(E)$-Vinyl iodide (3) 


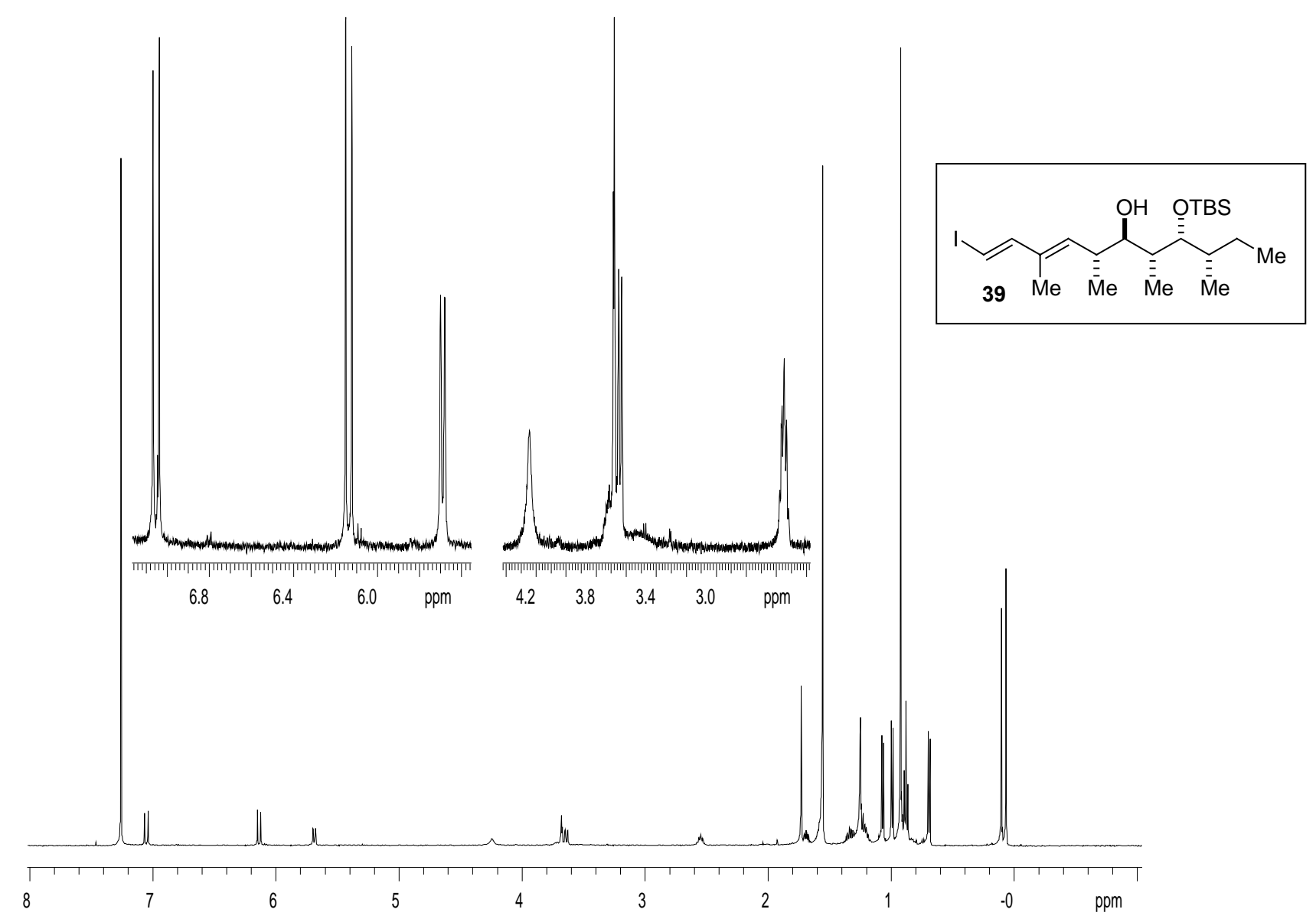

${ }^{1} \mathrm{H}$ NMR (300 MHz, $\left.\mathrm{CDCl}_{3}\right)-(E)$-Vinyl iodide (39)

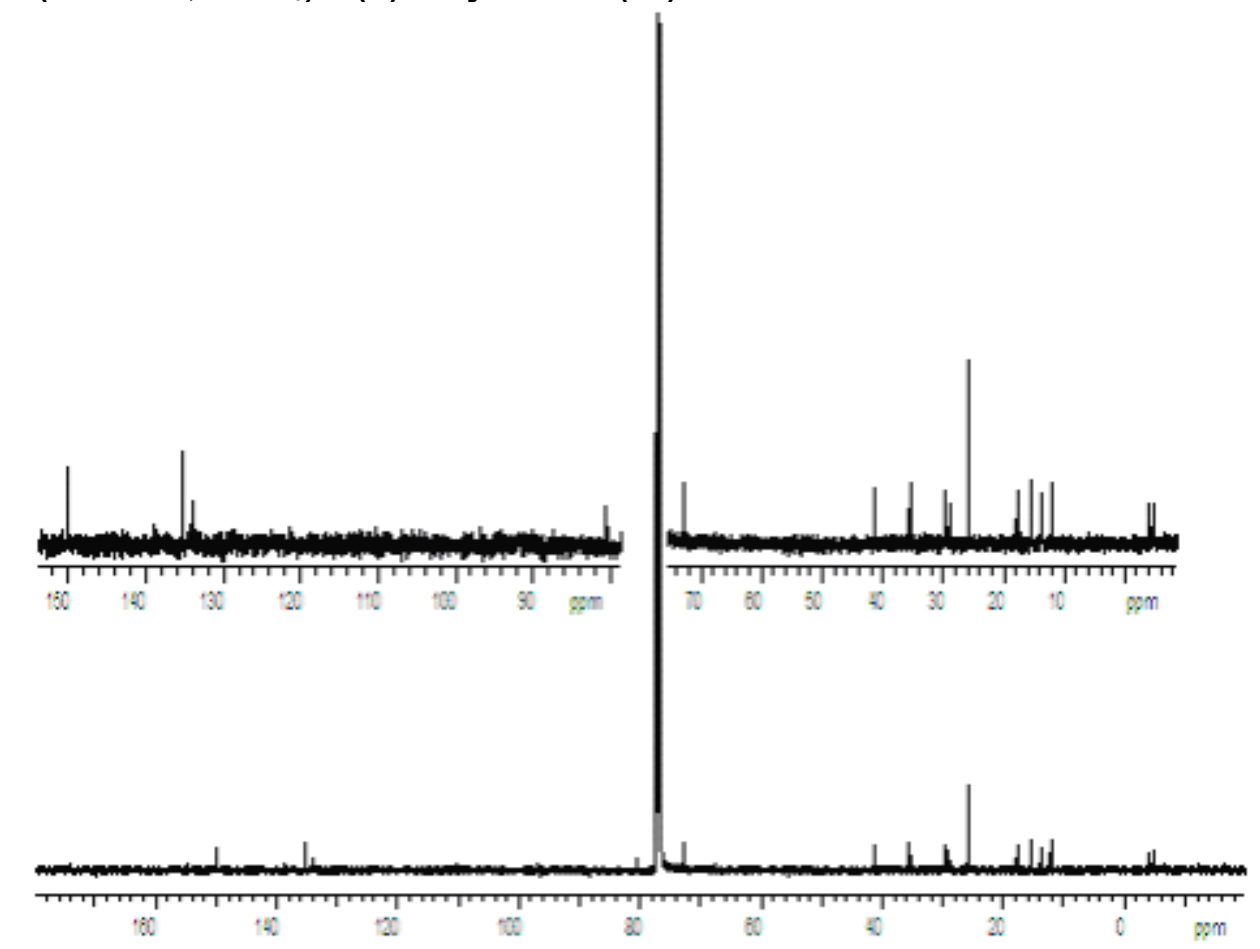

${ }^{13} \mathrm{C}$ NMR (75 MHz, $\left.\mathrm{CDCl}_{3}\right)-(E)$-Vinyl iodide (39) 

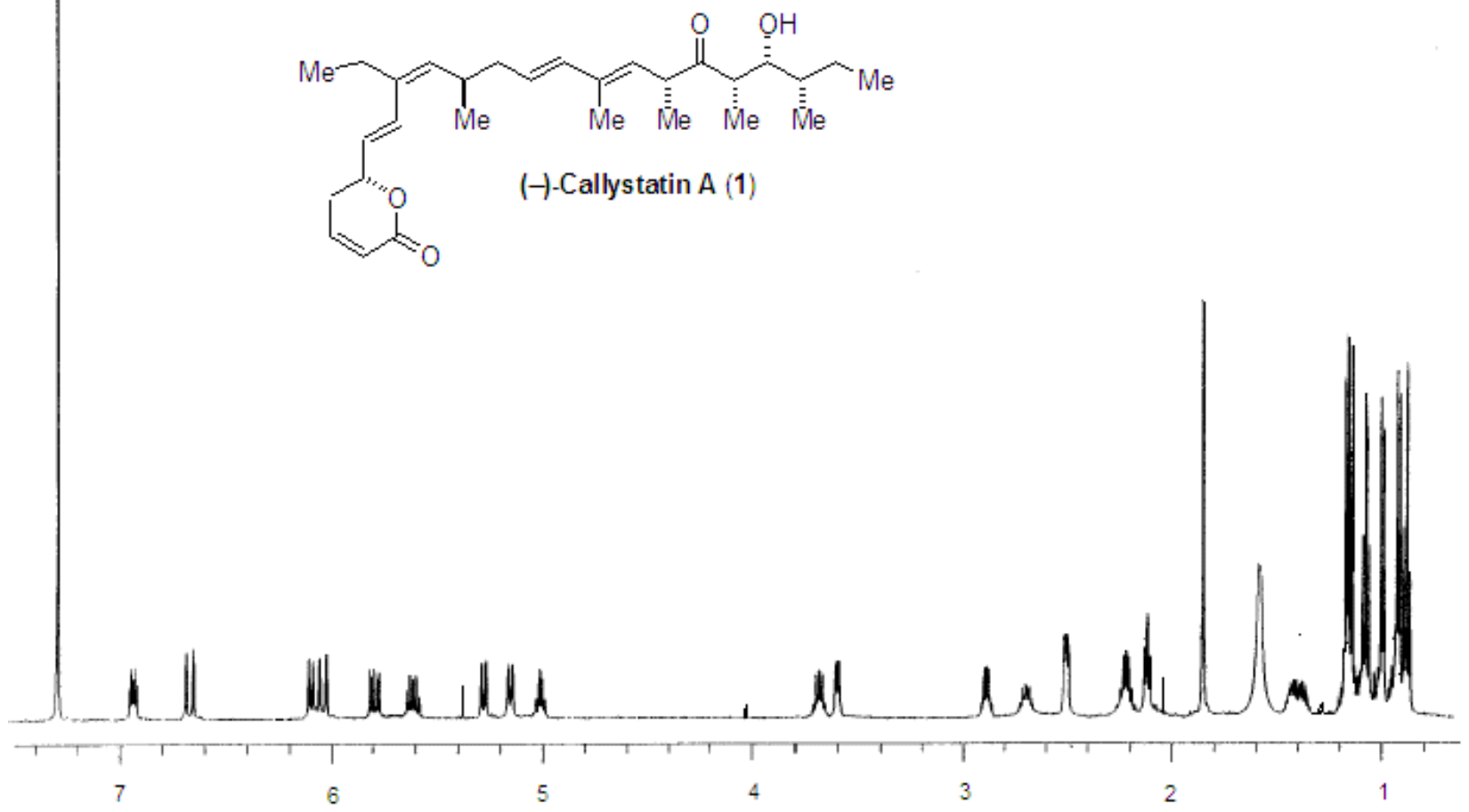

${ }^{1} \mathrm{H}$ NMR (300 MHz, $\left.\mathrm{CDCl}_{3}\right)$ - Callystatin A (1) 